\title{
THE LEgal FraMEWORK FOR CARBON CAPTURE AND STORAGE IN ALBERTA
}

\author{
Nigel Bankes, 'JenetTe Poschwatta, ${ }^{* *}$ \\ AND E. MITCHELL SHIER ${ }^{* * *}$
}

Carbon capture and storage (CCS) technologies are gaining currency as a means of disposing of greenhouse gases and helping states meet their international obligations under such instruments as the Kyoto Protocol. However, while the utility of these technologies has become increasingly evident, their relative novelty has meant that the legal issues surrounding their application have remained largely unresolved. This article examines the property, regulatory, and liability issues associated with CCS in an Alberta context. The authors draw upon existing law and practice in relation to analogous activities including enhanced oil recovery, acid gas disposal, and natural gas storage to identify changes and clarifications that might be desirable in order to develop an appropriate legal framework for CCS in Alberta.
Les technologies de capture et stockage de dioxyde de carbone (CSC) deviennent de plus en plus populaires pour éliminer les gaz à effet de serre et aider les États à respecter leurs obligations internationales en vertu d'ententes comme le Protocole de Kyoto. Cependant, bien que ces technologies s'avèrent de plus en plus utiles, en raison de leur nouveauté relative, les questions juridiques entourant leur application demeurent essentiellement non réglées. Cet article examine la propriété, la réglementation et les questions de responsabilité liées au CSC en Alberta. Les auteurs font appel aux lois et pratiques existantes relatives à des activités analogues, incluant la récupération assistées des hydrocarbures, l'élimination de gaz corrosifs et le stockage de gaz naturel dans le but d'identifier les changements et les clarifications pouvant être souhaitables pour le développement d'un cadre juridique convenant au CSC en Alberta.

\section{TABLE OF ConTENTS}

I. InTRODUCTION ................................. 586

II. THE Four StAGES OF CCS $\ldots \ldots \ldots \ldots \ldots \ldots \ldots \ldots \ldots \ldots$

A. CAPTURE ............................... 588

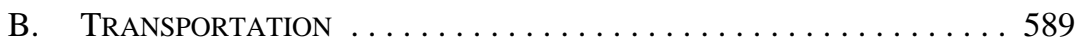

C. Storage ................................... 589

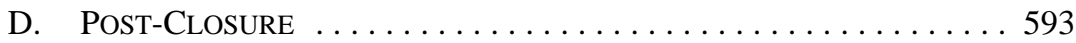

III. BARRIERS TO THE AdOPTION OF CCS $\ldots \ldots \ldots \ldots \ldots \ldots \ldots \ldots \ldots$

A. THREE ANALOGIES FOR CCS . . . . . . . . . . . . . . . . . . . 593

B. THE RISKS OF CCS $\ldots \ldots \ldots \ldots \ldots \ldots \ldots \ldots \ldots \ldots \ldots \ldots$

C. THE Legal CHARACTERIZATION OF

CARBon DioXide AND CCS ActivitiES . . . . . . . . . . . . 598

IV. The Property IsSUES . . . . . . . . . . . . . . . . . . . . . . . . . . . 599

A. Disposal into a Saline Aquifer $\ldots \ldots \ldots \ldots \ldots \ldots \ldots \ldots$

B. Disposal into a Depleted Oil and Gas

Reservoir Where There is No Split Title . . . . . . . . . . . . . . 604

C. Disposal into a Depleted Oil and Gas

RESERVOIR WHERE THERE IS A

Split Title/SEVEREd Estate . . . . . . . . . . . . . . . . . . 606

D. Surface Rights AND DisPosal Operations $\ldots \ldots \ldots \ldots 609$

* $\quad$ Professor of Law, University of Calgary.

** Research Associate, Canadian Institute of Resources Law, Calgary.

**** Partner, Heenan Blaikie, Calgary. 


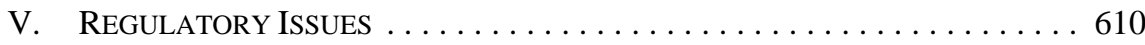

A. ApPROVAl OF $\mathrm{CO}_{2}$ Disposal/StORAGE PROJeCTS

AND InJECTION WELLS $\ldots \ldots \ldots \ldots \ldots \ldots \ldots \ldots \ldots \ldots \ldots \ldots$

B. Regulation Of THE ABANDONMENT OR

Post-InJECtion Phase of a CCS PROJeCt $\ldots \ldots \ldots \ldots \ldots .617$

VI. Liability Issues . . . . . . . . . . . . . . . . . . . . . . . 620

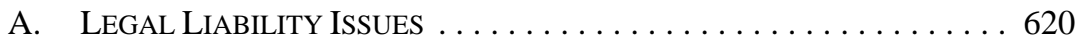

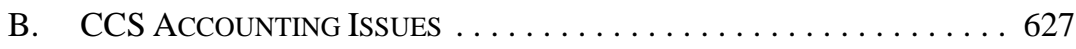

VII. CONCLUSIONS .................................... 629

\section{INTRODUCTION}

Carbon capture and storage (CCS) is one of a number of potential technological options ${ }^{1}$ to reduce anthropogenic emissions of carbon dioxide $\left(\mathrm{CO}_{2}\right){ }^{2}$ As such, CCS may help states meet the stabilization objective of the United Nations Framework Convention on Climate Change $^{3}$ and the quantified emission limitations of the Kyoto Protocol to the United Nations Framework Convention on Climate Change. ${ }^{4} \mathrm{CCS}$ refers to the capture of the $\mathrm{CO}_{2}$ produced by various industrial processes and the storage/disposal ${ }^{5}$ of that $\mathrm{CO}_{2}$ in a storage/disposal reservoir where it will remain for a long period of time without significant atmospheric leakage. ${ }^{6}$ While there exists a range of possible storage/disposal reservoirs including ocean storage/ disposal as well as potential industrial uses, this article deals only with the legal issues associated with geological storage/disposal.

Geological storage/disposal sites may be located onshore or offshore. For some states (for example, Norway and some member states of the European Union (EU)) offshore storage/

Other options include: (1) reducing energy consumption; (2) switching to less carbon-intensive fuels (e.g. coal to gas); (3) increasing use of non-carbon fuels (hydro, renewables, and nuclear); and (4) biological sequestration of carbon.

2 Unlike biological sequestration, which involves the uptake of $\mathrm{CO}_{2}$ from the atmosphere, CCS serves to avoid/reduce emissions.

39 May 1992, 1771 U.N.T.S. 107, 31 I.L.M. 849 (entered into force 21 March 1994).

411 December 1997, UN Doc. FCCC/CP/1997/7/Add.1, 37 I.L.M. 22 (entered into force 16 February 2005) [Kyoto Protocol].

5 In general we will use the term "storage/disposal" to draw attention to the fact that while the literature generally uses the term carbon capture and storage rather than carbon capture and disposal, the whole purpose of CCS is, in fact, disposal. The distinction is important in the legal and regulatory context since different rules may well apply to "storage" and "disposal" schemes. We will use the single term "storage" to refer to activities such as natural gas storage, where the goal really is storage rather than disposal.

${ }_{6}$ A key source is the Intergovernmental Panel on Climate Change (IPCC), online: $<$ http://www.ipcc.ch/ index.htm>. See IPCC, IPCC Special Report on Carbon Dioxide Capture and Storage, Prepared by Working Group III of the Intergovernmental Panel on Climate Change, B. Metz et al., eds. (Cambridge: Cambridge University Press, 2005), also available online: IPCC <http://www.ipcc.ch/ipccreports/ srccs.htm> [IPCC CSS Report]. Another accessible source is Mary Griffiths, Paul Cobb \& Tom MarrLaing, Carbon Capture and Storage: An arrow in the quiver or a silver bullet to combat climate change? A Canadian Primer (Drayton Valley, Alta.: Pembina Institute, 2005), online: The Pembina Institute <http://www.pembina.org/pub/584> [Pembina Primer]. Another source by a leading Canadian authority on CCS, and which emphasizes the policy challenges, is David W. Keith, Towards a Strategy for Implementing $\mathrm{CO}_{2}$ Capture and Storage in Canada, Environmental Protection Series, EPS/2/IC/1, 2002, Prepared for the Oil, Gas, and Energy Branch, Environment Canada (December 2002), online: University of Calgary <http://www.ucalgary.ca/ keith/papers/46.Keith.2002.StrategyForCCSinCanada. e.pdf $>$. 
disposal is the only large-scale option available, while for other states (for example, the United States, Canada, and Australia) onshore sites are more likely. ${ }^{7}$ The issue of offshore storage/ disposal gives rise to a range of questions under international law that need not be considered in the context of an onshore storage/disposal project. ${ }^{8}$

The CCS literature generally identifies up to four different phases in any CCS project: (1) capture; (2) transport (to the injection well); (3) injection; and (4) post-closure. This article focuses on stages 3 and 4 in the context of onshore CCS projects. The distinction between stage 3 and stage 4 is that stage 4 commences when active injection has ceased and the proponent has demonstrated site stability. Stage 4 is therefore concerned with the long-term storage/disposal of $\mathrm{CO}_{2}$ and with necessary monitoring of the site to detect leakage to the atmosphere. ${ }^{9}$

The balance of the article proceeds as follows. Part II provides a sketch of the key features of the four stages of CCS. Part III discusses the main barriers to the adoption of CCS. The next three parts of the article discuss three types of legal issues. Thus, Part IV deals with property issues, Part V with regulatory issues, and Part VI with liability issues. Much of the analysis is premised on the assumption that, in identifying and examining the legal issues associated with CCS, a great deal can be learned from analogous operations including natural gas storage, enhanced oil recovery (EOR), and acid gas disposal (AGD) schemes. ${ }^{10}$

7 International Energy Agency (IEA), Discussion Paper for 2nd IEA/CSLF Workshop on Legal Aspects of Carbon Capture and Storage, Paris, France, (17 October 2006), online: IEA <http://www.iea.org/ Textbase/work/ 2006/carbon/2.pdf> at 15 [IEA/CSLF Legal Aspects - Draft]. The final report was published in June 2007: IEA, Legal Aspects of Storing $\mathrm{CO}_{2}$ :Update and Recommendations (Paris: IEA, 2007) [IEA Legal Aspects - Final Report].

The questions include: Is the geological disposal of $\mathrm{CO}_{2}$ prohibited or regulated by the terms of relevant maritime conventions, including the United Nations Convention on the Law of the Sea, 12 October 1982, 1833 U.N.T.S. 3, 21 I.L.M. 1261 (entered into force 16 November 1994), the Convention on the Prevention of Marine Pollution by Dumping Wastes and Other Matter, 29 December 1972, 1046 U.N.T.S. 120, 11 I.L.M. 1294 (entered into force 30 August 1975) [London Convention 1972], or regional agreements such as the Convention for the Protection of the Marine Environment of the NorthEast Atlantic, 22 September 1992, 32 I.L.M. 1069 (entered into force 25 March 1998)? See also the 1996 Protocol to the London Convention 1972, 7 November 1996, 36 I.L.M. 1 (entered into force 24 March 2006), online: International Marine Organization (IMO) < http://www.imo.org/includes/blastData Only.asp/data_id\%3D19136/PROTOCOLAmended2006.doc $>$. The Protocol was amended effective 10 February 2007 to allow for geological sequestration projects: see online: IMO <http://www.imo.org/ home.asp?topic_id=1488>. There is a significant and growing literature on these questions. See e.g. Ray Purdy \& Richard Macrory, Geological carbon sequestration: critical legal issues, Tyndall Centre for Climate Change Research Working Paper No. 45 (January 2004), online: Tyndall Centre for Climate Change Research < http://www.tyndall.ac.uk/publications/working_papers/wp45.pdf >; Chris Hendriks, M.J. Mace \& Rogier Coenraads, Impacts of EU and International Law on the Implementation of Carbon Capture and Geological Storage in the European Union, ECS04057 (June 2005), online: $<$ http://pdf.wri.org/ccs_impact_of_eu_law_on.pdf>; IEALegal Aspects - Final Report, ibid., c. 3 and Annex 5.

$9 \quad$ Ministerial Council on Mineral and Petroleum Resources, Carbon Dioxide Capture and Geological Storage: Australian Regulatory Guiding Principles (2005) online: Australian Government; Department of Innovation, Science and Research <http://www.industry.gov.au/assets/documents/itrinternet/ Regulatory_Guiding_Principles_for_CCS20051124145652.pdf > at 8 [Australian Guiding Principles]. See also Nigel Bankes \& Jenette Poschwatta, “Carbon Capture and Storage in Alberta: Learning From the Acid Gas Disposal Analogy” (2007) 97 Resources 1, online: Canadian Institute of Resources Law $<$ http://www.ucalgary.ca/ cirl/pdf/Resources97.pdf>. We offer a brief discussion of AGD in Part III.A, below. 


\section{THE Four StAges OF CCS}

\section{A. CAPTURE}

Carbon capture is most likely to occur at large-point sources. These sources include large fossil fuel or biomass energy facilities, major $\mathrm{CO}_{2}$-emitting industries such as cement producers, refineries, iron and steel manufacturing, oil sands production and upgrading (including facilities to produce hydrogen from natural gas to use in the refining and oil sands upgrading process), and petrochemicals and natural gas production (especially where the gas stream includes a high $\mathrm{CO}_{2}$ content, for example, gas production from the Sleipner field and the Snohvit field, both located on the Norwegian shelf). The cost of capturing $\mathrm{CO}_{2}$ (including the costs of compression) represents the lion's share of the CCS process costs and may account for as much as 75 percent of overall CCS costs, although technological innovations may change these proportions. The IPCC estimates that capture costs will range between US\$ 5-115/tCO ${ }_{2}$ net captured, depending upon the type of project. ${ }^{11}$

All forms of capture involve a significant energy penalty since the capture process requires the expenditure of energy. ${ }^{12}$ Given the costs of capture, commentators suggest that early CCS projects should focus on those point sources that produce $\mathrm{CO}_{2}$ streams with a higher $\mathrm{CO}_{2}$ content since the per unit costs of capture will likely be lower. Such projects will include natural gas projects, where the methane stream has a high $\mathrm{CO}_{2}$ content which has to be removed to meet pipeline and marketing specifications, and petroleum-refining and upgrading projects which produce hydrogen from natural gas by a process known as steam methane reforming which produces a stream of nearly pure $\mathrm{CO}_{2} \cdot{ }^{13}$ Various incentives may be devised to encourage the adoption of capture technology, including carbon taxes and a cap and trade system. ${ }^{14}$

Some of the legal issues associated with the capture stage of CCS are intellectual property issues involved in the protection of the capture technology. Other issues relate to health and safety concerns arising from dealing with a compressed $\mathrm{CO}_{2}$ gas stream. These issues are not the subject of this article. ${ }^{15}$

11 IPCC CCS Report, supra note 6 at 11; Keith, supra note 6 at 7.

12 IPCC CCS Report, ibid. at 4. The nature of the penalty will vary with the technology and the purity of the $\mathrm{CO}_{2}$ stream. The IPCC CCS Report estimates a power plant equipped with a CCS system will need between 10 to 40 percent more energy than a plant of equivalent output without CCS.

$13 \quad$ Keith, supra note 6 at 10.

14 For a useful discussion of the various incentives that can be used to encourage adoption of CCS, see IEA Legal Aspects - Final Report, supra note 7, especially at 48-60. For the recently introduced incentive structure in Alberta, see the Specified Gas Emitters Regulation, Alta. Reg. 139/2007, which entered into force on 1 July 2007. The regulation applies to all industrial facilities in Alberta that emitted 100,000 tonnes or more of greenhouse gases in any year starting in 2003. Each established facility must reduce its average emissions intensity to 88 percent of its 2003 to 2005 baseline. Emission intensity reduction targets for new facilities (those that began operation after 31 December 2000) will be phased in over a six-year period. Facilities unable to comply with the target reduction may either purchase emission offsets, fund credits, or pay into a provincial fund to develop technology to reduce emissions.

15 The intellectual property issues are identified and discussed in IEA Legal Aspects — Final Report, supra note 7 at 43-48, Annex 3. 


\section{B. Transportation}

Once captured and compressed, $\mathrm{CO}_{2}$ can be readily transported from the capture site to a storage/disposal (injection) site. While various options may be feasible, large volumes are most likely to be transported by pipeline, at high pressure, in a dense or supercritical phase. Most jurisdictions regulate $\mathrm{CO}_{2}$ pipelines in the same manner as they regulate natural gas pipelines. ${ }^{16}$ For example, in Alberta, the construction and operation of an intra-provincial $\mathrm{CO}_{2}$ pipeline is regulated by the Alberta Energy and Utilities Board (AEUB) under the terms of the Pipeline Act. ${ }^{17}$ Similarly, an interprovincial or international $\mathrm{CO}_{2}$ pipeline (such as the Souris pipeline that provides $\mathrm{CO}_{2}$ for the Weyburn project) is regulated by the National Energy Board (NEB) under its Act. ${ }^{18}$ A key concern is to ensure that the $\mathrm{CO}_{2}$ stream is dried in order to eliminate the possibility of corrosion from the formation of carbonic acid.

Possible incentives to encourage this phase of CCS include public funding for $\mathrm{CO}_{2}$ pipeline infrastructure. For example, in Alberta there has been discussion of a possible $\mathrm{CO}_{2}$ pipeline to link the capture of oil sands-related emissions in the northern part of the province with enhanced oil recovery projects in the south. ${ }^{19}$

\section{STORAGE}

There are four main types of geological storage/disposal sites: (1) depleted oil and gas reservoirs; (2) deep saline formations; (3) (unminable) coal beds; and (4) salt caverns. Each has different characteristics and potential. In addition, and of particular interest in the short term, producing oil and gas reservoirs offer considerable opportunities for $\mathrm{CO}_{2}$ injection as part of EOR operations and perhaps enhanced gas recovery (EGR). Incremental revenue from these activities may be used to offset capture and storage costs. Further incentives that may stimulate this part of the CCS cycle include carbon taxes or a cap-and-trade system, as well as more targeted programs such as royalty incentives for EOR projects. ${ }^{20}$ Framework for States - Summary of Recommendations 2005, online: IOGCC <http://www. iogcc.state.ok.us/PDFS/CarbonCaptureand StorageReportandSummary.pdf> [IOGCC Report]. (this is subject to a number of exceptions, none of which are relevant here). While the Act does not define the term "substance," it is clearly a word of broad import that undoubtedly includes a pipeline designed to carry $\mathrm{CO}_{2}$. 


\section{ENHANCED OIL RECOVERY}

While varying from reservoir to reservoir, the primary recovery of oil will typically result in production of 5-15 percent of the original oil in place. ${ }^{21}$ Recovery may be enhanced by secondary recovery mechanisms (such as a water-flood operation) or enhanced still further by a tertiary recovery operation such as a $\mathrm{CO}_{2}$ miscible flood. As of 2004, there were about $80 \mathrm{CO}_{2}$-EOR projects operating around the world, most in the U.S. (especially in the Permian basin and using primarily natural, rather than anthropogenic, $\mathrm{CO}_{2}$ ) but with some operations in Canada, including the intensively studied Weyburn Project in the Williston Basin area of Saskatchewan. ${ }^{22}$

The most important obstacle to the widespread adoption of $\mathrm{CO}_{2}$-EOR projects is the availability of carbon dioxide. Given this constraint, $\mathrm{CO}_{2}$-EOR projects are typically operated with an eye to minimize $\mathrm{CO}_{2}$ usage and maximize $\mathrm{CO}_{2}$ recovery. ${ }^{23}$ If storage/disposal acquires a value that exceeds its EOR value, that objective will change as operators seek to maximize $\mathrm{CO}_{2}$ retention. A recent European study suggested that the storage/disposal capacity of reservoirs in the United Kingdom and Norwegian North Sea sectors would be 4.9 $\mathrm{GtCO}_{2}$, if they were operated to minimize $\mathrm{CO}_{2}$ usage, as opposed to $9.7 \mathrm{Gt}$ if the goal were to maximize storage/disposal. ${ }^{24}$ While these volumes may be relatively small when compared with other storage/disposal options, these reservoirs will likely serve as early storage/disposal targets since revenue from enhanced recovery will offset capture and storage costs. The same European study estimated that widespread application of $\mathrm{CO}_{2}$-EOR in selected fields in these two sectors might (disregarding economics) enhance recovery by between 4.6 and 9.4 billion barrels. ${ }^{25}$ In addition to enhanced recovery from oil reservoirs, there is likely some potential for EGR if $\mathrm{CO}_{2}$ were injected into depleted gas reservoirs.

21 The discussion in this paragraph is largely based on E. Tzimas et al., Enhanced Oil Recovery using Carbon Dioxide in the European Energy System, Institute for Energy, Petten, The Netherlands (December 2005), online: Institute for Energy <http://ie.jrc.cec.eu.int/publications/scientific_ publications/2005/EUR21895EN.pdf>. Similar studies prepared in the U.S. suggest similar potential for enhanced recovery if $\mathrm{CO}_{2}$ is more broadly available. The U.S. Department of Energy has commissioned ten basin studies for EOR potential. The reports are available online: U.S. Department of Energy <http://www.fossil.energy.gov/programs/oilgas/eor/Ten_Basin-Oriented_CO2-EOR_Assess ments.html>.

22 For further information on Weyburn, see the website of the Petroleum Technology Research Centre (PTRC), online: PTRC < http://www.ptrc.ca/weyburn_first.php>. The Weyburn Field covers about 70 square miles; original oil in place - 1.4 billion barrels; recovery prior to using $\mathrm{CO}_{2}-370$ million barrels; projected incremental recovery - 155 million barrels; projected $\mathrm{CO}_{2}$ injection — about 20 million tonnes (see Oilfield Statistics). The operator for the Weyburn project is Encana; the operator for the adjacent Midale project is Apache. Monitoring for the project includes a $10 \mathrm{~km}$ perimeter around the field.

23 For example, while the operators plan to inject about $20 \mathrm{Mt} \mathrm{CO}_{2}$ in the Weyburn EOR project, it is estimated that the storage capacity of the reservoir is about $45.15 \mathrm{Mt}$ : see PTRC, IEA GHG Weyburn $\mathrm{CO}_{2}$ Monitoring \& Storage Project Summary Report 2000-2004, vol. III, Proceedings of the 7th International Conference on Greenhouse Gas Control Technologies, Vancouver, Brisith Columbia, 5-9 September 2004, online: PTRC < http://www.ptrc.ca/siteimages/Summary_Report_2000_2004.pdf> at 149.

24 Tzimas et al., supra note 21 at 4.

25 Ibid. at 14. Relevant economic factors (including the price of oil, the costs of $\mathrm{CO}_{2}$, and the value of carbon credits) would affect the extent to which operators would actually adopt $\mathrm{CO}_{2}$-EOR. 
It is evident that at some point, an EOR or EGR operation may merge into a $\mathrm{CO}_{2}$ storage/disposal operation when oil or methane can no longer be produced economically. But it will likely be difficult to draw a bright line between these two activities. For example, it seems likely that any depleted reservoir, if subjected to $\mathrm{CO}_{2}$ "disposal" (in other words, a $\mathrm{CO}_{2}$ soak rather than a $\mathrm{CO}_{2}$ flood), may be re-entered at some point in the future and produce incremental quantities of hydrocarbons. ${ }^{26}$

\section{DEPLETED OIL AND GAS RESERVOIRS}

A depleted oil and gas reservoir may be used for long-term storage/disposal of $\mathrm{CO}_{2}$. Such reservoirs are attractive targets because their geological characteristics are well known and they are already connected to a pipeline infrastructure. The IPCC CCS Report estimates that oil and gas reservoirs may have a storage/disposal capacity of between $675 \mathrm{Gt}$ and $900 \mathrm{Gt}$ of $\mathrm{CO}_{2}{ }^{27}$ The In Salah gas project (Algeria), which commenced operations in 2004, is an example of a CCS project in a depleted reservoir. In this case, the $\mathrm{CO}_{2}$ stream (derived from the gas stream itself, which contains $\mathrm{CO}_{2}$ concentrations of between 1 and 9 percent) is injected into the aquifer zone of one of the shallow gas-producing reservoirs. ${ }^{28}$ Depleted oil and gas reservoirs have also been used in North America (and especially Alberta) for the disposal of acid gas waste streams from gas-processing facilities. ${ }^{29}$

\section{DEEP SALINE FORMATIONS}

Deep saline formations occur in sedimentary basins around the world and are not confined to hydrocarbon areas. The IPCC estimates that there exists at least 1,000 Gt capacity available, but that it may be as high at 10,000 Gt. Sleipner, the first commercial deep saline project, commenced operations in 1996 in the Norwegian sector of the North Sea. The

This possible method of characterizing the impact of CCS on recoveries was suggested at the IOGCC Meeting on Long-Term Storage of $\mathrm{CO}_{2}$ in Geologic Formations (Workshop Report), Alta., Utah (17-19 July 2002), online: $\mathrm{CO}_{2}$ Capture Project <http://www.co2captureproject.org/news/documents/IOGCC \%20CO2\%20Storage\%20Workshop.doc >. The concept is that a third opportunity for recovery falls between EOR and CCS. In this scenario, the pool could be "charged" with $\mathrm{CO}_{2}$ at the same level as would be anticipated in a disposal/storage situation. The charged field would then be left to a $\mathrm{CO}_{2}$ soak for a period of several years before reopening for additional recovery (possibly supplemented by additional $\mathrm{CO}_{2}$ injection). If this was a viable method of recovery, the additional recovery should be subject to continued capture and re-injection of all $\mathrm{CO}_{2}$ produced. The soak phase could then be characterized as a field revitalization rather than either storage or disposal of $\mathrm{CO}_{2}$, bringing the activity firmly within the conservation mandate of the AEUB. Maintenance of tenure may become an issue due to the extended time of the soak. It may be necessary to reward those companies willing to invest in the project by providing a future stake in the production. For Crown lands, a reward system could be set up to provide companies that invest in this process with a right of first refusal to reopen the field post-soak, subject to a condition of capturing all produced $\mathrm{CO}_{2}$ and an obligation to use the field for final disposal of $\mathrm{CO}_{2}$. This right of first refusal could be proportionate based on the $\mathrm{CO}_{2}$ captured and used in the soak. IPCC CCS Report, supra note 6 at 221. These figures might be increased by 25 percent if hypothesized undiscovered fields were included.

Fred Riddiford et al., "Monitoring Geological Storage: The In Salah Gas $\mathrm{CO}_{2}$ Storage Project,” online: University of Regina <http://uregina.ca/ghgt7/PDF/papers/nonpeer/529.pdf >.

Stefan Bachu \& Kristine Haug, "In Situ Characteristics of Acid-Gas Injection Operations in the Alberta Basin, Western Canada: Demonstration of $\mathrm{CO}_{2}$ Geological Storage" in Sally M. Benson, ed., Carbon Dioxide Capture for Storage in Deep Geologic Formations - Results from the $\mathrm{CO}_{2}$ Capture Project: Geologic Storage of Carbon Dioxide with Monitoring and Verification, vol. 2 (Amsterdam: Elsevier, 2005) 867. 
project injects about $1 \mathrm{Mt}$ of $\mathrm{CO}_{2}$ annually into the Utsira formation, about 1,000 metres below the seabed. ${ }^{30}$ Other commercial deep saline projects include some of the acid gas injection projects in North America. ${ }^{31}$

\section{STORAGE IN COAL}

Carbon dioxide injected into coal seams will displace methane adsorbed in the coal, thereby resulting in permanent sequestration unless the coal is subsequently mined, whereupon the pressure changes in the reservoir would cause the adsorbed $\mathrm{CO}_{2}$ to be released into the atmosphere. As with EOR and EGR projects, coal $\mathrm{CO}_{2}$ storage/disposal projects should produce a revenue stream in the form of sales methane, leading some to describe this type of operation as enhanced coal bed methane recovery (ECBM). Not all coal seams are suitable for $\mathrm{CO}_{2}$ injection and methane recovery. In particular, they must be "permeable and homogenous, with little faulting or folding." 32 The IPCC CCS Report acknowledges that there are no existing commercial $\mathrm{CO}_{2}$ coal projects, but estimates available storage/disposal as between $3 \mathrm{Gt}$ and $200 \mathrm{Gt}^{33}$

\section{SALT CAVERn StORAGE}

Salt caverns, like depleted oil and gas reservoirs, have long been used as gas storage facilities around the world, but the creation of such caverns is expensive and each cavern offers only limited storage capacity (for example, $0.5 \mathrm{Mt}$ ). Salt caverns are created when water is pumped into salt formations, thereby dissolving the salt. The resulting brine solution is pumped to the surface and disposed of through deep well injection. Given costs and limited capacity it seems unlikely that operators will make widespread use of this method of storage/disposal, notwithstanding that the performance of such structures as storage facilities is well known. ${ }^{34}$

\section{CONCLUSIONS ON STORAGE OPTIONS}

In sum, there exist several options for geological storage/disposal of $\mathrm{CO}_{2}$. Some of these options (EOR, EGR, and ECBM) offer a revenue stream that may offset capture and storage/disposal costs. In general, the technology for the various storage/disposal options is well known, with perhaps the greatest uncertainties associated with $\mathrm{CO}_{2}$ storage/disposal in coal.

The Sleipner Project is summarized in the IPCC CCS Report, supra note 6 at 202.

Discussed in Part III, below.

Pembina Primer, supra note 6 at 41.

IPCC CCS Report, supra note 6 at 197.

Stephan Bachu \& Leo Rothenburg, “Carbon Dioxide Sequestration in Salt Caverns: Capacity and Long Term Fate,” online: Alberta Geological Survey <http://www.ags.gov.ab.ca/activities/CO2/abstracts/ Mns_NETL_Conf_Bachu_and_Rothenburg.pdf $>$. The authors speculate that caverns might be used where there are large emission sources and no alternative storage options (and presumably where there is no developed economic $\mathrm{CO}_{2}$ pipeline infrastructure) and cite the example of the oil sands area of northeastern Alberta (at 1). 


\section{Post-Closure}

The post-closure stage refers to the long-term storage/disposal of $\mathrm{CO}_{2}$ once injection has come to an end. The principal need during this stage of the project is for the continued monitoring of the behaviour of the stored substances and the identification of any leaks. Monitoring techniques include 4D seismic and testing of $\mathrm{CO}_{2}$ levels in freshwater aquifers and soils. Although there is some scientific debate concerning the required duration of monitoring, it is likely these activities will need to occur over a period of decades, if not centuries. Remedial action may be required to deal with cases of leakage (for example, from abandoned wells). In order to encourage adoption of CCS, it will be necessary to adopt clear rules dealing with the allocation of liability for various types of potential harms and losses, including liability under a national and international emissions regimes, liability for catastrophic events, and liability for any required remedial action.

\section{BARRIERS TO THE AdOPTION OF CCS}

The principal barrier to the widespread adoption of CCS is the absence of adequate economic incentives to capture large point sources of $\mathrm{CO}_{2}$ emissions. However, this is likely not the only barrier. Other barriers include the risks associated with CCS and the public perception of those risks, as well as the regulatory management of risk. David Keith, for example, makes the point this way:

Technological capability is a necessary but insufficient condition for CCS to play a major role in mitigating $\mathrm{CO}_{2}$ emissions.... CCS must evolve ... into a large-scale technological system for managing fossil fuel carbon.... such a technological system [needs inter alia] regulations that are accepted by industry and are able to achieve broad public understanding and acceptance.... Efforts to build a robust regulatory environment for geological storage cannot wait until the technology is ready for large-scale application. ${ }^{35}$

Similarly, the Australian Guiding Principles note that “current uncertainty about a guiding framework that will apply to CCS projects means that industry is unlikely to invest in the technology.... industry and the community cannot have confidence in the costs or in the rights and obligations that might apply for management of CCS.»36

The balance of this section of the article does three things. First, it describes some of the analogies to CCS that we might have in mind while thinking about CCS projects, namely (a) EOR, (b) gas storage, and (c) AGD. Second, we describe the risks associated with CCS. Third, we offer some preliminary comments on the different regulatory responses to the classification of $\mathrm{CO}_{2}$.

\section{A. THREE ANALOGIES FOR CCS}

We have already discussed EOR above. It represents a direct analogy for the capture, transportation, and injection phases of CCS. The most significant difference is that EOR is not aimed at the long-term disposal or sequestration of $\mathrm{CO}_{2}$. Indeed, quite the contrary; an 
operator may have an incentive to seek to produce and re-use injected $\mathrm{CO}_{2}$ in another reservoir.

Many jurisdictions also have long-standing experience with natural gas storage schemes. While the goal of gas storage is also not that of long-term storage, we may draw upon the regulatory schemes for storage operations in thinking about the acquisition of storage/disposal rights and the regulatory approval for such schemes.

A few jurisdictions, notably Alberta and British Columbia, ${ }^{37}$ also have considerable experience with acid gas disposal. Some commentators consider that AGD schemes offer a particularly important and useful analogy precisely because (unlike the first two examples) CCS and AGD schemes share the same goal of long-term disposal of a waste stream. ${ }^{38}$

Acid gas disposal or injection refers to the injection and geological disposal of mixed streams of $\mathrm{CO}_{2}$ and hydrogen sulphide $\left(\mathrm{H}_{2} \mathrm{~S}\right)$. AGD began in Alberta in 1989 as a response to the dual challenge posed by the need to reduce sulphur dioxide emissions from natural gas processing plants and by falling prices for elemental sulphur produced as part of conventional processing. In essence, the idea is to take the sulphur emissions stream and inject it back into the ground. While the principal emissions target has always been $\mathrm{H}_{2} \mathrm{~S}$, the waste stream from the typical processing plant also contains $\mathrm{CO}_{2}$ as an impurity. The injection ratios for approved injection projects vary between 83 percent $\mathrm{H}_{2} \mathrm{~S}$ and 14 percent $\mathrm{CO}_{2}$ to 2 percent $\mathrm{H}_{2} \mathrm{~S}$ and 95 percent $\mathrm{CO}_{2}$. Since 1989, the AEUB has approved 48 AGD schemes for a variety of target formations, including saline formations (26), depleted oil and gas reservoirs (18), and in four cases, into the water leg of a producing oil reservoir. ${ }^{39}$ Those living close to processing plants see AGD schemes as providing significant environmental

Note that many more jurisdictions have experience in and a regulatory framework for dealing with other forms of geological disposal such as the disposal of brine, oil field waste, and other forms of municipal and industrial waste. These analogies will prove particularly important in the U.S. where the Environmental Protection Agency (EPA) has taken the position that $\mathrm{CO}_{2}$ injection wells should be treated as Class V experimental wells under the terms of the Underground Injection Control (UIC) Regulation of the federal Safe Drinking Water Act, 42 U.S.C. \$201; the literature on the U.S. UIC is extensive. See e.g. U.S. EPA, Technical Program Overview: Underground Injection Control Regulations, EPA 816-R-02-025 (revised July 2001), online: U.S. EPA <http://www.epa.gov/ safewater/uic/pdfs/techguide_uic_tec_overview_uic_regs.pdf> [Technical Program Overview]; Earle A. "Rusty" Herbert, "The Regulation of Deep-Well Injection: A Changing Environment Beneath the Surface” (1996) 14 Pace Envtl. L. Rev. 169; U.S. EPA, Class I Underground Injection Control Program: Study of the Risks Associated with Class I Underground Injection Wells, EPA 816-R-01-007 (March 2001), online: U.S.EPA <http://www.epa.gov/safewater/uic/classonestudy.pdf > [EPA — Study of the Risks]; John A. App, “The Regulatory Climate Governing the Disposal of Liquid Wastes in Deep Geologic Formations: A Paradigm for Regulations for the Subsurface Storage of $\mathrm{CO}_{2}$ ?" in Benson, supra note 29, 1173; David W. Keith et al., "Regulating the Underground Injection of $\mathrm{CO}_{2}$ " (2005) 39 Environmental Science \& Technology 499A, describing Florida's deep injection of municipal wastewater. See also Mark Anthony de Figueiredo, The Liability of Carbon Dioxide Storage, Ph.D Dissertation, Massachusetts Institute of Technology (February 2007), online: Carbon Capture \& Sequestration Technologies @ MIT <http://sequestration.mit.edu/pdf/Mark_de_Figueiredo_PhD_ Dissertation.pdf $>$ at 79-100.

38 See e.g. Sam Wong et al., "Economics of Acid Gas Reinjection: An Innovative $\mathrm{CO}_{2}$ Storage Opportunity," online: University of Calgary <http://www.ucalgary.ca/ keith/papers/56.Wong.2003. EconomicsOfAcidGasReinjection.e.pdf> 
and health benefits, since such schemes offer the opportunity to reduce sulphurous emissions to essentially zero. ${ }^{40}$

\section{B. THE RISKS OF CCS}

Carbon dioxide is an essential part of the natural carbon cycle and a necessary ingredient in the life-cycle of plants and animals through the processes of photosynthesis and respiration. ${ }^{41}$ The normal exhalation of breath contains approximately 3.5 percent $\mathrm{CO}_{2} \cdot{ }^{42} \mathrm{At}$ normal atmospheric conditions, $\mathrm{CO}_{2}$ exists as a gas. It is 1.5 times denser than air, is nonflammable, and at low concentrations is generally considered to be odourless. As a normal but minor (370ppmv) constituent of air it is considered harmless. Higher concentrations and long-term exposure to elevated $\mathrm{CO}_{2}$ levels can be hazardous $\left(\mathrm{CO}_{2}\right.$ acts as an asphyxiant in the range of 7-10 percent), and there are also hazards associated with handling $\mathrm{CO}_{2}$ under pressure. The release of concentrated amounts of $\mathrm{CO}_{2}$ may pose risks since $\mathrm{CO}_{2}$ is denser than air and tends to accumulate in low-lying areas.

The risks associated with CCS fall into two broad categories: (1) the operational risks such as the environmental, health, and safety risks associated with the capture, transportation, and injection of $\mathrm{CO}_{2}$, and management during the post-injection phase; and (2) the global risks associated with CCS failure.

The global risks arise from uncertainty surrounding the effectiveness of CCS as a method of reducing GHG emissions. Based on observations of naturally occurring $\mathrm{CO}_{2}$ storage, the risk that CCS will fail on a global scale is very low. ${ }^{43}$ The IPCC CCS Report states that, in sites that are well selected, designed, operated, and monitored, it is "very likely" that 99 percent of stored $\mathrm{CO}_{2}$ will be retained for the first 100 years and that it is "likely" that 99 percent of stored $\mathrm{CO}_{2}$ will be retained for the first 1,000 years. ${ }^{44}$

Operational risks include: the risk of harm to human or animal health and the environment due to the localized escape of $\mathrm{CO}_{2}$ at the surface, the chemical effects of $\mathrm{CO}_{2}$ due to subsurface release, and the quantity-based effects due to increased pressure or fluid displacement by injected $\mathrm{CO}_{2}{ }^{45}$ Possible risks associated with surface release include

There are several AEUB decisions in which interveners have attempted to have the AEUB require operators to adopt AGD in preference to some alternative emissions control technology. See e.g. the discussions in AEUB, Decision 99-27: Petro Canada Oil and Gas Application to Install Compressors at the Wilson Creek Gas Plant and at LSD 3-19-43-4 W5M, Wilson Creek Field (1 November 1999) at 8.

CCS Report, supra note 6 at 385

Ibid. at 17.

There are several naturally occurring $\mathrm{CO}_{2}$ storage sites. For example, about $200 \mathrm{MtCO}_{2}$ has thought to have been trapped more than 65 million years ago in the Pisgah Anticline northeast of the Jackson Dome, Mississippi. Many of the petroleum basins show retention time longer than 10 million years: ibid. at 244-45.

44 "Very likely" is a probability between 90 and 99 percent while "likely" is a probability of 66 to 90 percent: ibid. at 12, 14 .

45 See Elizabeth J. Wilson, Timothy L. Johnson \& David W. Keith, "Regulating the Ultimate Sink: Managing the Risks of Geologic $\mathrm{CO}_{2}$ Storage” (2003) 37 Environmental Science \& Technology 3476; Elizabeth J. Wilson \& David W. Keith, Geologic Carbon Storage: Understanding the Rules of the Underground, online: University of Calgary <http://www.ucalgary.ca/ keith/papers/58.Wilson.2003. GeologicCarbonStorage.f.pdf>. 
suffocation of humans or animals and ecosystem impacts such as damage to tree or grass root systems. ${ }^{46}$ Release of $\mathrm{CO}_{2}$ in the subsurface may result in metal mobilization or changes to groundwater chemistry. Quantity-based risks include ground heave, induced seismicity, displacement of groundwater resources, and damage to hydrocarbon production. The overall risk for each of these is proportional to the magnitude of the potential hazard and the probability that the hazard will occur.

The local impact of a release is greatly dependent upon the location of the release and the resulting concentration of $\mathrm{CO}_{2}$. Episodic or localized releases are more likely to have significant impact than generalized, low-level releases. The risk of a particular localized release occurring may be measured by looking at comparable activities. For example, the injection of $\mathrm{CO}_{2}$ or any other fluid deep underground necessarily causes changes in pressure and displacement of other fluids. Experience with injection of other fluids, such as waste water, into the deep subsurface provides a mechanism for understanding the risk of $\mathrm{CO}_{2}$ injection. ${ }^{47}$ Contamination of groundwater by brines displaced by fluid injection is rare, and it is expected that the same will apply to the injection of $\mathrm{CO}_{2} \cdot{ }^{48}$

Fault activation is primarily dependent upon the quantity and rate of injection, rather than the type of fluid injected. The underground injection of fluids or $\mathrm{CO}_{2}$ into porous rock at pressures higher than original formation pressures may induce fracturing and fault slip. ${ }^{49} \mathrm{In}$ the past, there have been occurrences of micro-seismic activity as the result of fluid injection. ${ }^{50}$ The picture is different for EOR, where no significant seismic effects have been attributed to the injection of $\mathrm{CO}_{2}$, even in situations where reservoir pressures exceed the original formation pressure. ${ }^{51}$

Injection wells and abandoned wells have been identified as one of the most probable leakage pathways for $\mathrm{CO}_{2}{ }^{52}$ The risk of leakage through abandoned wells is related to the number of wells in the storage/disposal area, their depth, and the method and materials used

Natural seeps typically occur in highly fractured volcanic zones, quite unlike the interior of a stable sedimentary basin which is the likely location for $\mathrm{CO}_{2}$ storage. One such seep, in central Italy, has a release rate high enough to be lethal to plants and animals. At least 10 people have died in the Lazio region over the past 20 years: IPCC CSS Report, supra note 6 at 247. A series of earthquakes created a natural seep near Mammoth Mountain, California. Within a year, 4 hectares of pine trees were discovered to be losing their needles, and 8 years later the area of dead and dying trees had expanded to 40 hectares: IPCC CSS Report, supra note 6 at 248. The most catastrophic event was the venting at Lake Nyos, Cameroon which killed about 1,700 people: IPCC CSS Report, supra note 6 at 308.

$47 \quad$ App, supra note 37 at 1173.

$48 \quad$ IPCC CCS Report, supra note 6 at 248.

$49 \quad$ Ibid. at 249.

50 See Jürgen E. Streit, Anthony F. Siggins \& Brian J. Evans, “Predicting and Monitoring Geomechanical Effects of $\mathrm{CO}_{2}$ Injection” in Benson, supra note 29, 751.

$51 \quad$ IPCC CCS Report, supra note 6 at 249.

52 Ibid. at 228; see also George W. Scherer et al., "Leakage of $\mathrm{CO}_{2}$ Through Abandoned Wells: Role of Corrosion of Cement” in Benson, supra note 29, 827. 
in abandonment. ${ }^{53}$ Regulators will need to be satisfied as to the integrity of abandonment materials and procedures, but these challenges are relatively well known since reservoirs containing abandoned wells have been, and continue to be, used as gas storage facilities in many parts of the world. The risk of leakage is reduced by a thorough knowledge of all abandoned wells in a target area. While our understanding of abandoned well-bore behaviour over long periods of time is limited, there is a great deal known on how to deal with well leaks and blow-outs should they occur. Studies of natural gas storage operations show that only 10 of approximately 600 storage reservoirs operated in Canada, the U.S., and Europe have been identified as having experienced leakage, most from wellbore integrity problems. ${ }^{54}$ Monitoring using observation wells and surface monitoring is effective in controlling the risks associated with natural gas storage.

The risks associated with CCS must be understood within the context of the trapping mechanisms involved. There are four main mechanisms to trap $\mathrm{CO}_{2}$ in the subsurface. ${ }^{55}$ First, there are structural traps where a physical barrier prevents migration of $\mathrm{CO}_{2}$ to the surface. The physical barrier, or cap rock, commonly takes the form of impermeable layers of shale or evaporties. Second, at the pore scale, capillary trapping immobilizes a substantial fraction of $\mathrm{CO}_{2}$ as tiny isolated bubbles in a residual phase. Third, the $\mathrm{CO}_{2}$ will dissolve into other pore fluids, such as brines and hydrocarbons, over a period of decades to centuries. In this state, the $\mathrm{CO}_{2}$ cannot be released without active intervention. And finally, over hundreds to thousands of years, the dissolved $\mathrm{CO}_{2}$ may react with minerals in the rock, where it will precipitate as a new carbonate mineral. ${ }^{56}$ At that point, the $\mathrm{CO}_{2}$ is permanently trapped as rock. The critical point to observe with the geological and chemical trapping mechanisms is that the highest risk for leakage occurs early in the process. As time passes, the $\mathrm{CO}_{2}$ in the subsurface becomes more stable and there is a corresponding reduction of risk.

Most risks associated with CCS are small and continue to decrease over time; however, in rare cases, leakage may occur. In these situations, a remediation plan will be needed to stop the leak and to prevent human or ecosystem impact. Risks may be higher in areas where there are a number of abandoned wells. In Alberta, most, if not all, CCS areas will have numerous abandoned wells that must be monitored and maintained to ensure long-term safe sequestration of $\mathrm{CO}_{2}$.

Well density is particularly high in North America (e.g. more than 350,000 wells in Alberta and over one million wells in Texas) and much lower in other parts of the world (e.g. just over 16,000 wells in the North Sea): David Hawkins \& Stefan Bachu, "Deployment of large-scale $\mathrm{CO}_{2}$ geological storage: Do we know enough to start now?" (Paper presented to the GHGT-8, 8th International Conference on Greenhouse Gas Control Technologies, Trondheim, Norway, 19-22 June 2006), online: <https://events. adm.ntnu.no/ei/viewpdf.esp?id=24\&file=d\%3A\%5CAmlink\%5CEVENTWIN\%5Cdocs\%5Cpdf\%5 C950Final00299\%2Epdf> at 3; Pembina Primer, supra note 6 at 38.

54 See Kent F. Perry, "Natural Gas Storage Industry Experience and Technology: Potential Application to $\mathrm{CO}_{2}$ Geologic Storage" in Benson, supra note 29, 815.

55 Dr. S. Julio Friedmann, “Technical feasibility of rapid deployment of geological carbon sequestration,” Written testimony submitted to the House Energy and Commerce Committee, Energy and Air Quality Sub-committee Hearing: Carbon Capture and Sequestration: An Overview (6 March 2007), online: Committee on Energy and Commerce <http://energycommerce.house.gov/cmte_mtgs/110_eaq-Hrg. 030607.Friedmann-Testimony.pdf $>$ at 2 .

56 If the $\mathrm{CO}_{2}$ is injected into unusable coal seams, it will physically absorb onto the coal, sometimes displacing other gases such as methane. 


\section{The Legal Characterization of Carbon Dioxide AND CCS ACTIVITIES}

Carbon dioxide has well-known commercial applications. In addition to its use in EOR projects, as already discussed, it is also used for carbonated beverages, fire extinguishers, and refrigeration, and dry ice. These established uses of $\mathrm{CO}_{2}$, combined with our understanding of the generally non-toxic nature of $\mathrm{CO}_{2}$, lead some reports and proponents of CCS to emphasize that $\mathrm{CO}_{2}$ should be treated as a commodity and not as a pollutant or as waste. ${ }^{57}$ The reality, however, is that the regulatory treatment of $\mathrm{CO}_{2}$ is not consistent. For example, the federal government of Canada has chosen to list $\mathrm{CO}_{2}$ as a "toxic substance" under the terms of the Canadian Environmental Protection Act, 1999, ${ }^{58}$ and while the EPA in the U.S. has proven reluctant to regulate $\mathrm{CO}_{2}$ as a pollutant under the Clean Air Act, ${ }^{59}$ several states and non-governmental organizations have had some success in their efforts to have the EPA reverse its stance.$^{60}$ By contrast, the preamble to Alberta's Climate Change and Emissions and Management $A c t^{61}$ emphasizes the non-toxic nature of atmospheric $\mathrm{CO}_{2}$, and Alberta does not classify $\mathrm{CO}_{2}$ as a pollutant, waste, or hazardous waste when in the form of an atmospheric gas. ${ }^{62}$ The CCEMA currently requires reporting of $\mathrm{CO}_{2}$ and other specified gases into the environment at or in excess of the level prescribed in the Specified Gas Reporting Standard. ${ }^{63}$ Internationally, under the Basel Convention, atmospheric $\mathrm{CO}_{2}$ is not considered a waste. ${ }^{64}$

The general conclusion here is that the categorization of $\mathrm{CO}_{2}$ and $\mathrm{CCS}$ projects may vary given the type of activity and project. It will be important to ensure that the classification will not lead to an inappropriate level of regulation that may represent an unreasonable barrier to

$57 \quad$ IOGCC Report, supra note 16 at 40-41, 51.

$58 \quad$ S.C. 1999, c. 33 at Schedule 1; Order Adding Toxic Substances to Schedule 1 to the Canadian Environmental Protection Act, 1999, P.C. 2005-2037, C. Gaz. 2005.II.139, S.O.R./2005-345. Pub. L. 89-272, §101(8), 79 Stat. 992, as am. by 84 Stat. 1690, 91 Stat. 791, 42 U.S.C. §7521(a)(1).

$60 \quad$ In Massachusetts v. Environmental Protection Agency, 49 U.S. 1438 (2007), the U.S. Supreme Court allowed the plaintiffs to proceed with their action seeking to compel the EPA to develop $\mathrm{CO}_{2}$ emission regulations for new vehicles.

61 S.A. 2003, c. C-16.7 as am. by the Climate Change and Emissions Management Amendment Act, S.A. 2007, c. 4 [CCEMA], which came into force on 20 April 2007. The CCEMA does not dovetail well with the Environmental Protection and Enhancement Act, R.S.A. 2000, c. E-12 [EPEA]. That Act does not treat general $\mathrm{CO}_{2}$ emissions as a hazardous waste, but would still apply in certain circumstances. For example, a specific release of $\mathrm{CO}_{2}$ that caused an adverse effect would be reportable under s. 110 . $\mathrm{CO}_{2}$ in Alberta is only a hazardous waste when it falls into one of the categories specified in the Waste Control Regulation, Reg. 192/96. Examples are compressed or liquefied $\mathrm{CO}_{2}$ that is discarded or offspecification.

63 Alberta Environment, Specified Gas Reporting Standard (March 2007), online: Alberta Government <http://www3.gov.ab.ca/env/air/pubs/ghg_specified_gas_reporting_standard.pdf>.

64 Basel Convention on the Control of Transboundary Movements of Hazardous Wastes and Their Disposal, 22 March 1989, 1673 U.N.T.S. 126, 28 I.L.M. 657 (entered into force 5 May 1992), text available online: <http://www.basel.int/> [Basel Convention]. The U.S. is not a party to the Basel Convention, but it arrives at the same conclusion under the bilateral Agreement between the Government of Canada and the Government of the United States of America concerning the Transboundary Movement of Hazardous Waste, 28 October 1986, Can. T.S. 1986 No. 39 (entered into force 8 November 1986). This agreement applies only to hazardous wastes and municipal waste. The $\mathrm{CO}_{2}$ import/export from the U.S. to Canada which occurs as part of the Weyburn EOR project would not trigger this agreement since the $\mathrm{CO}_{2}$ in this project is not regarded as waste, and certainly not as hazardous waste. 
the adoption of CCS technology. At the same time, the regulatory framework for CCS needs to be responsive to the risks and uncertainties associated with CCS projects.

\section{THE Property Issues ${ }^{65}$}

The concept of ownership is often explained as a bundle of rights, ${ }^{66}$ including a set of rights to use the property for a variety of different purposes. One of the "use rights" held by the surface owner of real property is undoubtedly the right to use lands to store substances including wastes (subject of course to any applicable regulations). ${ }^{67}$ Such a right includes the right to give or deny (subject only to the state's right of eminent domain) to others the right to engage in that activity. This concept seems straightforward, and the same principles should apply to the subsurface disposal of a waste substance (or the subsurface storage of a more valuable non-waste stream), whether disposal is to a saline aquifer or a depleted oil and gas reservoir.

This section of the article deals with the application of these principles to a number of different scenarios. The article deals first with the easy cases, in which the target formation is owned by a single owner. Such cases include disposal into an aquifer (owned by the Crown) and disposal into a depleted reservoir for which there are no severed estates (for example, the petroleum, natural gas, and coal rights have not been split). The more difficult cases of split title or severed estates will then be considered. Finally, the article looks at related surface rights issues. The analysis draws upon the legal treatment of the analogous problems associated with gas storage rights and acid gas disposal. The province sought to clarify the legal issues associated with gas storage rights in a set of amendments to the Mines and Minerals $A c t^{68}$ in $1994 .{ }^{69}$ We argue here that those amendments, while effective in dealing with storage issues, do not deal with disposal rights.

In general, this section of the article tries to answer two types of questions. The first question is: From whom must the proponent or operator of a CCS project acquire a $\mathrm{CO}_{2}$ disposal right? In answering that question, we must keep in mind both the owner of the fee simple estate and any relevant working interest owners. The second question relates to the form of the disposal right, particularly where the Crown is the relevant owner: How can we expect the Crown to dispose of its disposal rights?

\section{A. Disposal into a Saline Aquifer}

The property rights issues associated with disposal into a saline aquifer will be straightforward in any jurisdiction where there is a statutory provision vesting ownership

65 For further and comprehensive discussion of some of these issues in an Australian context, see Minter Ellison, Carbon Capture and Storage: Report to the Australian Greenhouse Office on Property Rights and Associated Liability Issues (Canberra, Austl.: Australian Greenhouse Office, 2005), online: Australian Government; Department of Climate Change <http://www.greenhouse.gov.au/ccs/ publications/pubs/ccs.pdf>.

66 See e.g. Bruce Ziff, Principles of Property Law, 4th ed. (Toronto: Carswell, 2006) at 2.

67 See also EPEA, supra note 61, s. 182, confirming that "[n]o person shall dispose of waste on any land owned by another person unless the owner of that land agrees to the disposal of the waste on the land.”

68 R.S.A. 2000, c. M-17 [MMA].

69 Mines and Minerals Amendment Act, 1994, S.A. 1994, c. 22. 
rights in relation to water in the Crown. ${ }^{70}$ Section 3(2) of Alberta's Water Act ${ }^{71}$ declares that: "The property in and the right to the diversion and use of all water in the Province is vested in Her Majesty in right of Alberta.”

The term "water" is not confined to potable water, and the definition of water in the Act expressly includes water found on or under the ground. A recent decision of the Supreme Court of Canada relied on this section to conclude that "connate water" is owned by the Crown and that gas dissolved in the connate water is owned by the Crown, rather than by the owner of either the petroleum or the natural gas in a hydrocarbon reservoir. ${ }^{72}$ Given these legal rules, it seems fairly clear that an operator who proposes to inject $\mathrm{CO}_{2}$ into an aquifer must acquire that right from the Crown, regardless of who may own the petroleum and natural gas rights in relation to these lands. It also seems likely that the operator will only need to deal with the Crown, since it is highly unlikely that any other party will have the equivalent of an oil and gas working interest in or to the aquifer.

However, if the Crown owns the $\mathrm{CO}_{2}$ disposal rights, how will a CCS operator acquire that right? There is both a practical and a normative aspect to this question. The practical issue is one that will be of most concern to the operator. One might expect that a CCS operator would acquire the right, under the Water Act, but the Act is not structured to accommodate this form of right, and thus it seems more likely that a disposal right (if "right" is the correct term) will be acquired under the $M M A .^{73}$ Current practice in relation to AGD schemes supports this conclusion.

The normative aspect is concerned with the question of how the Crown ought to dispose of rights to a scarce resource (disposal space). The claim here is that the Crown has welldefined disposition rules for granting oil and gas rights and gas storage rights. To this point,

70 Or at least they will be straightforward if we make the assumption that the permission of the owner of the water is a sufficient permission. This issue was raised tangentially in Chance v. BP Chemicals Inc., 670 N.E.2d 985 (Ohio Sup. Ct. 1996) [Chance]. In Chance the plaintiffs were adjacent landowners who sued BP Chemicals Inc. (BP) as the operator of several deep injection wells alleging that the injection plume had migrated under their lands and inter alia constituted an actionable trespass. The Court rejected the claim on the grounds that the plaintiffs had not been able to establish an actionable trespass. One of BP's defences was that it was injecting into a brine formation and that the brine waters were "waters of the state" within the meaning of the relevant Ohio statute (at 992). The Court took the view that this assertion, even if correct, could not constitute a complete defence (at 992):

To the extent that appellee appears to be arguing that the way the injectate disperses into the native brine serves to insulate appellee from all liability in all circumstances, we reject appellee's contention. The native brine exists naturally in the porous sandstone into which the injecting is done. The injectate displaces and mixes with the brine in the injection zone. Appellants have a property interest in the rock into which the injectate is placed, albeit a potentially limited one, depending on whether appellants' ownership rights are absolute. If appellee's act of placing the injectate into the rock interferes with appellants' reasonable and foreseeable use of their properties, appellee could be liable regardless of the way the injectate mixes with the native brine.

71 R.S.A. 2000, c. W-3. Given the decision in Chance, ibid., it might be prudent to amend this provision of the Water Act to add a declaratory clause to the effect that "the property in and the right to the diversion and use of all water includes the right to dispose of substances into that water."

72 Anderson v. Amoco Canada Oil and Gas, 2004 SCC 49, [2004] 3 S.C.R. 3 at paras. 12-13, 42 [Anderson].

$73 \quad$ Supra note 68. 
at least, the Crown deals with injection/disposal rights much more casually. We argue that the Crown should put in place a clearer system for disposing of disposal rights.

The following paragraphs expand on each of these points.

At the risk of oversimplifying things we may say that the regulatory universe of the Water Act comprises two things: (1) approvals of diversions, and (2) approval of activities that affect water bodies. It seems clear that the injection of $\mathrm{CO}_{2}$ does not fall within the definition of a diversion, ${ }^{74}$ but it also seems fair to say that the concept of an activity requiring an approval, while technically broad enough to embrace a $\mathrm{CO}_{2}$ injection well, is designed to deal with activities that affect surface waters and potable ground water, rather than deep saline aquifers. ${ }^{75}$

It seems more likely, therefore, that the Crown will choose to follow current practice in relation to AGD schemes and authorize $\mathrm{CO}_{2}$ disposal operations pursuant to s. 56 of the MMA. Section 56 provides as follows:

\section{Injection wells}

56(1) Subject to section 57 [this is the section that seeks to clarify the ownership of storage rights and is discussed further in Part IV.C of this article], a person has, as against the Crown in right of Alberta,

(a) the right to use a well or drill a well for the injection of any substance into an underground formation, if the person is required by or has the approval of the Alberta Energy and Utilities Board to do so ....

(2) A person who exercises a right referred to in subsection (1)(a)

(a) shall indemnify the Crown in right of Alberta for loss or damage suffered by the Crown in respect of any claims or demands made by reason of anything done by that person or any other person on that person's behalf in the exercise or purported exercise of that right, and

(b) shall abandon the well when so directed or authorized by the Alberta Energy and Utilities Board, in accordance with the directions of the Board. ${ }^{76}$

This is a rather curious section. It seems to operate as a general approval or licence and does not, on its face, contemplate the grant of any further form of right. Rather, it anticipates that exercise of the right is dependent upon AEUB approval, thereby conflating what are

74 Section 1(1)(m)(i) of the Water Act defines a "diversion of water" as "the impoundment, storage, consumption, taking or removal of water for any purpose, except the taking or removal for the sole purpose of removing an ice jam, drainage, flood control, erosion control or channel realignment." Furthermore, the regulations to the Act exempt a diversion of saline groundwater from the provisions of the Act: see Water (Ministerial) Regulation, Alta. Reg. 205/98, Sch. 3 at 1(e).

75 That said, Sch. 1 of the Water (Ministerial) Regulation, ibid., contains an extensive list of "activities" that are exempt from the need to acquire an approval. The Regulations do not exempt a $\mathrm{CO}_{2}$ injection well. It is clear from the definition in the Act that a $\mathrm{CO}_{2}$ injection well does not qualify as a water well for the purposes of the Act. MMA, supra note 68, s. 56. 
ordinarily thought of as two separate issues: (1) the property right to engage in an activity, and (2) the regulatory approval of that activity.

Part V of the article, below, discusses the AEUB's regulatory approval mechanism in more detail; however, for present purposes it is important to anticipate that discussion in one particular. The relevant AEUB guide, Directive $065,{ }^{77}$ requires that an applicant for approval of a disposal scheme must provide evidence of the applicant's right to dispose into the proposed zone in the following forms: (1) for unleased Crown land, a letter of consent from the Crown; (2) for freehold lands, consent from the freehold mineral holder; ${ }^{78}$ and (3) for leased lands where the lease is held by a person other than the applicant, a letter of consent from the leaseholder. This AEUB requirement leads in turn to a practice in which Alberta Energy issues so-called "letters of consent" to parties who wish to engage in injection operations.

The consent letter ${ }^{79}$ is a short, standard form which states that "authorization is granted for acid gas disposal into the xx formation," subject to five conditions. The first two conditions are linked and require that the approval needs to be validated by the addressee acquiring a well licence from the AEUB within six months, in the absence of which the authorization will be null and void whereupon the addressee will need to make a fresh application. The third condition stipulates that the addressee cannot test or produce hydrocarbons from any zone not under lease, and that if unanticipated hydrocarbons are encountered, all operations must cease and any information disclosed to the public via the AEUB.$^{80}$ Fourth, all data relating to operations in undisposed Crown land is to be submitted to the AEUB (and thence to the public). The fifth condition simply stipulates that the operation, including licensing and ultimate abandonment, must also meet the AEUB's

AEUB Directive 065: Resources Applications for Conventional Oil and Gas Reservoirs (July 2007) at 117 [Directive 065]. Effective 1 January 2007, the AEUB has been realigned into two separate regulatory bodies, the Energy Resources Conservation Board (ERCB), which regulates the energy industry, and the Alberta Utilities Commission (AUC), which regulates the utilities industry. As part of this realignment the title pages of all existing AEUB directives now carry the new ERCB logo. However, no other changes have been made to the directives, and they continue to refer to the "EUB." As new editions of the directives are issued, these references will be changed. All Directives can be found on the ERCB's website online: ERCB <http://www.ercb.ca/portal/server.pt>.

The Directive does not specify what the approach should be in the event that the mineral estate has been severed into different component elements.

79 Alberta Energy uses a standard form consent letter for acid gas disposal in undisposed Crown lands: Personal Communication, Dave France, Alberta Energy (4 January 2007), enclosing a copy of the consent letter currently in use [available from the authors]. What is the legal character of this consent letter? It would seem to be a licence in the property law sense of that term; i.e. the letter permits an activity that would otherwise be a trespass: Thomas v. Sorel (1673) Vaugh. 330. Thus, while other Crown agreements are generally understood to confer rights in the form of a profit à prendre, the rights conferred by a consent letter do not confer an interest in land.

80 Presumably this is to ensure that the addressee does not have a competitive advantage in any subsequent Crown sale; the disclosure tracks the requirements that apply in the event of a trespassory testing. On trespass against Crown lands, see Alberta Energy, Information Letter 2005-26: "Trespass on Petroleum and Natural Gas and Oil Sands Rights” (18 October 2005), online: Alberta Energy <http://inform. energy.gov.ab.ca/Documents/Published/IL-2005-26.pdf>. 
requirements. Finally, and although not listed as a condition, the standard form also reiterates the indemnity requirement of s. 56(2)(a) of the $M M A .^{81}$

Several observations on this somewhat extraordinary way of affording rights to Crown lands seem in order. First, the letter clearly characterizes the activity as that of "disposal" and not "storage." Second, there does not appear to be any charge or fee associated with the grant of these disposal rights. ${ }^{82}$ This represents a significant departure from Crown practice in relation to the disposition of other forms of rights. Given that pore storage/disposal space represents a limited and potentially scarce resource, it is not clear why rights to this resource are allocated as if it were a free good. Third, neither the $M M A$ nor the letter expressly addresses the duration of the right, although perhaps it might be said that, implicitly, the right of disposal continues for as long as the addressee retains an AEUB well licence in good standing - in other words, until abandonment. Fourth, while both the statute and the letter require the addressee to indemnify the Crown, it is not clear that the indemnity is couched in broad enough terms to completely protect the public interest. Finally, neither the statute nor the letter deal with issues of assignment. Are we to assume that the letter confers a personal and non-assignable right? Or are we to assume that the right is assignable in conjunction with an assignment of the relevant well licence ${ }^{83}$

In sum, the procedure for acquiring disposal rights from the Crown is informal and ad hoc, and it will likely be necessary to revisit this issue before CCS is widely adopted. In doing so, it may be possible to draw upon modern gas storage legislation. ${ }^{84}$ For example, recent legislation in Nova Scotia ${ }^{85}$ provides a scheme whereby a party may apply for a one-year storage area licence, which affords the licensee the exclusive right to conduct activities to evaluate the storage potential of the licensed lands. Assuming that the area proves up, the licensee may then apply for a 20-year (renewable) storage area lease. Similarly, Ontario’s

Supra note 76 and accompanying text. Actually the language of the letter does not quite track that of the statute. Here is the indemnity text from the letter (supra note 79):

Under Section 56(2) of the Mines and Minerals Act the Crown shall be indemnified for loss and damage suffered by the Crown and in respect of any claims made against by reason of anything done by you or anyone on your behalf in the exercise or purported exercise of the rights granted herein.

Neither the statute not the letter seems particularly well drafted if the Crown's goal is to obtain a broad indemnity. In particular, the language of the statute seems to be confined to those cases in which the Crown suffers a loss as a result of a claim or demand made by a third party; i.e. it does not seem to cover losses that the Crown itself may suffer. The letter, on the other hand, tries to rectify this by adding the word "and" to the text but then omits the word "Crown" in the phrase "any claims made against [the Crown?] by reason." Note as well that the letter does not address the duration of the indemnity: Is it perpetual? Does it cease upon abandonment? What happens upon the transfer of the well licence? Thus, the Schedule to the Mines and Minerals Administration Regulation, Alta. Reg. 262/97, refers to the fees charged for the issuance of agreements but is silent with respect to letters of consent. The general provisions of the MMA and the regulations dealing with transfers would not seem to be relevant since these deal with assignment of agreements, and a s. 56 disposal right is not an "agreement" within the meaning of the Act since an "agreement" is something that gives rights in respect of a mineral. We do not suggest the Alberta model for disposing of storage rights since in most cases (see infra note 105) gas storage rights are granted by means of a gas unit amendment to an underlying agreement. Underground Hydrocarbons Storage Act, S.N.S. 2001, c. 37. However, while this Act creates a useful regulatory framework for storage rights (and it does not address disposal of non-hydrocarbons), it ducks the important question of ownership of storage rights. Indeed the Act seems to proceed on the basis that the Crown owns storage without explicitly vesting such rights in the Crown (s. 17 dealing with vesting orders seems to relate to property other than the storage right itself). 
legislation provides for the grant of a storage lease to store listed substances (which substances do not include $\mathrm{CO}_{2}$ ) in "underground geological formations located on Crown

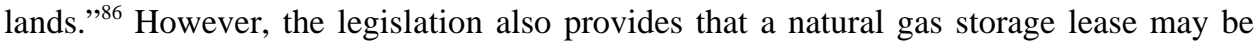
disposed of by tender, in which case the tender bid shall provide for two competitive variables: the cash bonus and a storage rental, calculated by reference to the amount of calculated storage space available. ${ }^{87}$ Ontario storage leases are granted for a 10 -year renewable term.

\section{B. DISPOSAL INTO A DEPLETED OIL AND GAS RESERVOIR WHERE THERE IS NO SPLIT TITLE}

If we assume there is a single owner of the mines and minerals estate, it seems relatively clear that a CCS operator must obtain the consent of that owner in order to commence an operation. ${ }^{88}$ That owner may be the Crown or a private owner.

Where the Crown is the owner it seems that the most likely way for the Crown to authorize a $\mathrm{CO}_{2}$ disposal project would be by way of a letter of consent, under s. 56 of the $M M A$, as discussed in the previous section. In addition, in order to avoid potential liability concerns, our operator will likely require ${ }^{89}$ or consider it prudent to acquire consents from any parties holding outstanding working interests in the pool (if any) who may be affected by the proposed operation.

Where the mines and minerals estate is privately held, an owner will likely provide the necessary consent either by way of a specific grant of disposal rights, or (and perhaps more likely) as one of the bundle of rights contained in the words of grant of a typical oil and gas lease. Indeed, given the fact that any $\mathrm{CO}_{2}$ "disposal” into an oil and gas reservoir will likely trigger some incremental recovery, there would be good reason for an operator to ensure that it had acquired more than just $\mathrm{CO}_{2}$ injection rights.

This raises the question of the extent to which freehold oil and gas lease forms typically grant disposal rights. We cannot provide a complete answer to that question here, but we can comment on one lease form. Two parts of the lease are important: the granting clause and the habendum. The Canadian Association of Petroleum Landmen (CAPL) 1999 lease $^{90}$ provides

Exploration Licences, Production and Storage Leases for Oil and Gas in Ontario, Ont. Reg. 263/02, s. 16(1); these are regulations to the Mining Act, R.S.O. 1990, c. M-14.

Proposed Australian $\mathrm{CO}_{2}$ disposal legislation is discussed in IEA Legal Aspects - Final Report, supra note 7 at 31-34.

The assumption here is that Alberta adopts the so-called English rule, pursuant to which storage rights are held by the owner of a severed mineral estate and not by the surface owner. The case law and literature supporting this view include Little v. Western Transfer and Storage Company (1922), 69 D.L.R. 364 (Alta. S.C. (A.D.)) and N. J. Stewart, "The Reservation or Exception of Mines and Minerals" (1962) 40 Can. Bar Rev. 328. The position is different in many American states.

See the discussion in of the AEUB's requirements in Part V, below.

CAPL, Petroleum and Natural Gas Lease and Grant (1999), online: CAPL <http://www.landman.ca/ store/capl_publication_list.php>. It is possible that other lease forms will offer a more extensive right to dispose and store substances. One example is a Shell lease form which affords the lessee the right to "store ... and dispose of" substances. But in at least some lease forms this right is confined to "leased substances" and while such substances include gaseous substances "whether hydrocarbons or not" this term could hardly extend to $\mathrm{CO}_{2}$ from an industrial source. 
that the lessor leases and grants exclusively to the lessee its rights and title in the leased substances:

[T] ogether with the exclusive right and privilege to explore for, drill for, operate, produce, win, take, remove, store, treat and dispose of the Leased Substances and the right to inject substances into the Lands for the purposes of obtaining, maintaining or increasing production of the Leased Substances from the Lands, the Pooled Lands or the Unitized Lands and to store and recover any substances injected into the Lands. ${ }^{91}$

This form of lease clearly permits the lessee to inject $\mathrm{CO}_{2}$ (whatever the source of the $\mathrm{CO}_{2}$; in other words, it is not confined to $\mathrm{CO}_{2}$ produced along with the leased substances) but it would not appear to allow a lessee to inject $\mathrm{CO}_{2}$ for disposal purposes since the purpose of the injection must be to enhance the recovery of leased substances. ${ }^{92}$ Similarly, while the lessee clearly has the right to store injected substances, the working rights do not expressly grant the right to dispose. On the other hand, the lease language does make it clear that the lessee would also be able to produce injected $\mathrm{CO}_{2}$ and use it, for example, for an EOR operation in another pool.

The CAPL lease is continued in force at the end of the primary term by "Operations." "Operations" are defined to include injecting substances (subject to the same purposive limitation as above) or "the recovery of any injected substances." 93 When operations so defined cease, the lease will automatically come to an end.

If a CCS operator needs the consent of the owner of the mines and minerals estate, however, there is also the question of the areal extent of the required consents. It seems evident that this cannot be confined to the bottom-hole location of the injection well, but must also extend to any area of the oil and gas reservoir to which the $\mathrm{CO}_{2}$ plume may extend. ${ }^{94}$ This supposition triggers a further question: What is the position if the CCS operator has identified a prospective formation for disposal but the mineral rights owners will

Ibid. The definition of leased substances is not confined to hydrocarbons but includes all materials and substances produced in association with the hydrocarbons. This would certainly include any natural $\mathrm{CO}_{2}$ in the reservoir.

92 For relevant U.S. case law, see Crawford v. Hrabe, 44 P.3d 442 (Sup. Ct. 2002): where a lease is silent as to the right to use off lease water for injection purposes, such a right might be implied as part of the implied duties (in U.S. law) of a prudent operator, provided that injection is for EOR purposes; such an implication is not likely (since the prudent operator rationale does not hold) where the off lease water is being brought on to the lease for disposal purposes: Farragaut v. Massey, 612 So. 2d 325 (Miss. Sup. Ct. 1992).

93 Supra note 90.

94 The rationale for this is that injecting a substance that migrates under another's land is prima facie a trespass absent a licence or some other form of entitlement: see Kennedy et al., "Tort Liability in Waterflood Operations” (1966) 5 Alta. L. Rev. 52. There are perhaps counter arguments. One argument is a sort of reverse or negative rule of capture argument to the effect that since no liability attaches to a person who drains from another's land, no liability should attach where a substance migrates under another's land: Howard R. Williams \& Charles J. Meyers, Williams \& Meyers Oil and Gas Law, Prepared by Patrick H. Martin \& Bruce M. Kramer (New York: Matthew Bender, 1998) vol. 1 at $\S 204.5$. The Supreme Court of Ohio rejected the application of the negative rule of capture in the deep well injection case in Chance, supra note 70. Another argument would be to say that the adjacent owner is only protected by a liability rule and not a property rule and thus cannot claim an injunction against the injecting party and can only claim damages to the extent of any proven loss. For the classic article on the difference between the different forms of entitlement, see Guido Calabresi \& A. Douglas Melamed, "Property Rules, Liability Rules, and Inalienability: One View of the Cathedral” (1972) 85 Harv. L. Rev. 1089. 
not agree to grant the necessary rights? Can the operator seek to acquire such a disposal right using expropriation or similar legislation? Or suppose that our operator has acquired disposal rights within a portion of the reservoir but cannot acquire rights for the balance of the reservoir? Can our operator seek the equivalent of a compulsory unitization order with respect to its proposed disposal operation ${ }^{95}$

It is well known that Alberta's compulsory unitization legislation has never been proclaimed, ${ }^{96}$ but it is also the case that when the MMA was amended in 1994 to deal with a suite of gas storage issues, the proposals did not include a compulsory acquisition scheme to facilitate assembling a storage project. ${ }^{97}$ This makes Alberta somewhat unusual since many jurisdictions in both Canada and the U.S. allow an operator to expropriate the necessary interests (surface and subsurface) in order to implement a storage project. ${ }^{98}$ Some statutory schemes also deal with third- party access to such storage once created. ${ }^{99}$ Such schemes might in principle be made to fit cases of $\mathrm{CO}_{2}$ disposal, although they will likely require amendment to ensure that the statutory scheme applies to cases of disposal as well as storage, and applies to gases other than hydrocarbons.

\section{DISPOSAL INTO A DEPLETED OIL AND GAS RESERVOIR WHERE THERE IS A SPLIT TITLE/SEVERED ESTATE}

The Borys ${ }^{100}$ and Anderson ${ }^{101}$ decisions confirm that there are many examples in Alberta of split title or severed estates; that is, situations in which the fee estate in some or all of the natural gas, petroleum, and coal is held in different titles in relation to the same quarter section of land. In a case of split title, one of the questions that the operator of a disposal project will pose is this: From whom do I need to acquire disposal rights? Can I acquire such a right from either the gas owner or the petroleum owner, or must I acquire the right from both?

This scenario may be of lesser concern in relation to a disposal proposal rather than an EOR-driven unitization or a gas storage proposal (because of concerns that a non-party to the arrangement will produce stored gas), but that may depend upon the relevant rules: property versus liability, etc. The unproclaimed sections may be found in the Oil and Gas Conservation Amendment Act, R.S.A. 2000, c. 24 (Supp.).

Glen Acorn \& Michael W.Ekelund, “An Overview of Alberta’s Recent Legislation on Natural Gas Royalty Simplification and Gas Storage” (1995) 33 Alta. L. Rev. 342 at 363: "[the section] does not ... provide for procedures similar to those for compulsory unitization by which recalcitrant title owners can be forced into participation in a storage scheme. If a storage scheme is to be conducted under a unit agreement, all title owners will have to be parties; there can be no "windows" in the unit area where unit operation is converted to a storage scheme." In Canada, see e.g. Ontario Energy Board Act, S.O. 1998, c. 15, s. 38 [OEB Act]. Relevant U.S. storage legislation is listed in the IOGCC Report, supra note 16, App. 5.

99 See e.g. Ontario, OEB Act, ibid., s. 39; but note as well recent discussion concluding that it may be unnecessary to regulate the availability and continue with utility-based pricing of storage if there is a sufficiently robust market: Ontario Energy Board (OEB), Natural Gas Electricity Interface Review, Decision with Reasons, OEB File No. EB-2005-0551 (7 November 2006), online: OEB <http:www. oeb.gov.on.ca/documents/cases/EB-2005-0551/Decision_Orders/dec_reasons_071106.pdf>. Borys v. Canadian Pacific Railway Co., [1953] A.C. 217 (P.C.) [Borys]. 
Uncertainty as to the correct answer to this question in the context of storage rights ${ }^{102}$ led the province to enact a declaratory amendment to the MMA in $1994 .{ }^{103}$ This amendment was clearly intended to address privately owned mineral rights as well as Crown mineral rights. ${ }^{104}$ For present purposes it must be understood how that legislation clarified the position, and then it can be considered whether the legislation also clarified the position in relation to disposal rights.

The 1994 amendments clarified three things. First, the legislation confirmed that "a person [who] owns the title to petroleum and natural gas in any land" also owns "the storage rights with respect to every underground formation within that land.” 105 The MMA defines storage rights as "the right to inject fluid mineral substances into a subsurface reservoir for the purpose of storage." ${ }^{106}$ Second, the legislation provides that where title is split between a gas owner and a petroleum owner, the owners of the separate estates are to be treated as "co-owners of the storage rights with respect to every underground formation within that land." ${ }^{107}$ But what does that mean? In their discussion of the section, Acorn and Ekelund comment that the section "deliberately does not state the nature of the co-ownership as being joint or otherwise. In practical terms this means that a storage scheme cannot proceed in such a case unless both co-owners are parties to the contractual arrangements. It leaves the matter of compensation of each of them to negotiation." ${ }^{108}$ But this comment ought to be taken a litle further. First, there are only two forms of co-ownership in Alberta: joint tenancy and tenancy in common, and there is a statutory presumption in favour of a tenancy in common. ${ }^{109}$ Second, as a matter of law, any tenant in common can make use of the estate and, in the absence of equitable waste, cannot be restrained from doing so by any other co-owner. ${ }^{110}$ Third, any co-owner owes a duty to account for more than any just share of rents or profits received. ${ }^{111}$ Thus, while Acorn and Ekelund, the principal architects of the legislation, may

The case law and literature referred to in supra note 88, may confirm that the holder of a severed mineral estate owns the storage rights vis-à-vis the surface owner, but are not helpful in deciding between the competing claims of the owners of different severed estates.

See supra note 69. The legislation (now MMA, supra note 68, s. 57) is discussed in Acorn \& Ekelund, supra note 97 at 360-64. See also Robert J. McKinnon, "The Interplay Between Production and Underground Storage Rights in Alberta” (1998) 36 Alta. L. Rev. 400. A contribution that pre-dates these amendments and is principally concerned with royalty calculation issues is Colin Q. Winter, "Albertan Gas Storage Reservoirs: A New Direction for Royalty Administration” (1993) 31 Alta. L. Rev. 107. While much of the MMA deals exclusively with Crown minerals, s. 2(b) makes it plain that the Act also applies "where the context so permits or requires, to all wells, mines, quarries and minerals in Alberta" (MMA, ibid.).

Ibid., s. 57(1)(a). This makes it crystal clear (at least prospectively) that Alberta adheres to the so-called "English" rule: see supra note 88. In addition to the three points discussed in the text, the amendment also creates a special rule (now MMA, supra note 68, s. 57(2)) dealing with storage caverns (i.e. salt caverns). MMA, ibid., s. 1(1)(z).

Ibid., s. 57(1)(b).

Acorn \& Ekelund, supra note 97 at 362-63.

Law of Property Act, R.S.A. 2000, c. L-7, s. 8. That said, a strict reading of this section would suggest that the presumption does not apply to a co-ownership created by statute; however, the idea that a right of survivorship might apply to a statutorily created co-ownership estate will surely be resisted by any court.

110 Job v. Potton (1875), 20 L.R. Eq. 84.

111 Osachuk v. Osachuk, [1971] 2 W.W.R. 481 (Man. C.A.); Law of Property Act, supra note 109, s. $17(2)(c)$. This of course begs the question of what a "just share" will be in the present context. In the usual case the just share will be referable to the percentage undivided interest of each party, but here the 
be correct when they assert that "[i]n practical terms"112 an operator will require the consent of both owners (because that will be the risk-averse approach), it is far from clear that they are correct as a matter of law.

Third, the legislation clarifies the position of the Crown vis-à-vis its lessees. Thus, s. 57(5) of the MMA makes it clear that a typical Crown oil and gas lessee or licensee does not own storage rights. Instead, the subsection provides that storage rights must be acquired expressly, most likely by way of a gas storage (unit) agreement which confers these additional rights on the Crown lessee. ${ }^{113}$

We can now consider whether these clarifications would also apply to a $\mathrm{CO}_{2}$ disposal operation.

There are several reasons for thinking that this package of amendments will not cover all cases of $\mathrm{CO}_{2}$ disposal. First, the commentary from Acorn and Ekelund makes it clear that these amendments were designed to deal with problems that had arisen in the context of gas storage, not disposal of other substances. Second, the amendments apply to storage rights, and, as we have seen, the term "storage right" is defined as the right to inject "fluid mineral substances" into a reservoir. ${ }^{114}$ "Fluid mineral substances" are defined, in turn, to mean "a fluid substance consisting of a mineral or of a product obtained from a mineral by processing or otherwise." ${ }^{\prime 15}$ It seems fairly clear that if a produced natural gas stream contained $\mathrm{CO}_{2}$, and if the $\mathrm{CO}_{2}$ were separated from that stream for compression (to form a liquid) and injection, then the resulting product would fall within the definition of a fluid mineral substance. ${ }^{116}$ However, it seems equally clear that $\mathrm{CO}_{2}$ captured from an industrial process, such as a thermal generating plant, would not fall within this definition. Third, the amendments deal with storage, and storage and disposal are two different things. ${ }^{117}$ The MMA does not define "storage," and while s. 1(2) of the MMA purports to allow the Minister

statute offers no guidance. Should we assume that the petroleum and gas owners each have a 50 percent interest?

112 Acorn \& Ekelund, supra note 97 at 362.

113 The subsection actually suggests that storage rights may be acquired in one of three ways: (1) by way of a unit agreement; (2) by way of a contract under s. 9(a) of the Act; (3) or by way of an agreement issued with the authorization of the Lieutenant Governor in Council. For Crown unit agreements, see s. 102 of the MMA, which provides that an agreement may cover not only the recovery of minerals but also "the use of the subsurface reservoir for the purposes of storage of fluid mineral substances and the combining of interests in the storage rights in respect of that subsurface reservoir” (s. 102(1)(b)). The Crown's standard form storage agreement is available online: Alberta Energy <http://www.energy. gov.ab.ca/Tenure/forms/unitgasagreement.pdf>. MMA, ibid., s. 1(1)(z).

Ibid., s. 1(1)(h).

This is in accord with Acorn \& Ekelund, supra note 97 at 361, who note that the definition of fluid mineral substances "[a]t the very least” embraces "natural gas and ... residue gas, ethane, propane, butanes, pentanes plus, a natural gas liquids mix and carbon dioxide obtained from natural gas.” The authors gloss over the "fluid" aspect of the concept.

See e.g. Acorn \& Ekelund, ibid. at 361, who after referring to the definition of "storage rights," go on to say that "[i]t follows, or should follow, from the definition that storage is distinguishable from disposal because 'storage' connotes an eventual recovery from the place of storage where 'disposal' does not.” In support of this interpretation, one might refer to s. 39 of the Oil and Gas Conservation Act, R.S.A. 2000, c. O-6 [OGCA] (discussed further in Part V, below) which clearly distinguishes between a series of activities, including "storage" and "disposal." 
to determine the purpose for which a mineral substance was injected, all the evidence suggests that this section is designed to permit the Minister to distinguish between injection for storage purposes and injection for conservation reasons. ${ }^{118}$

\section{SURFACE RightS AND DisPosAl OPERATIONS}

The final property law issue is concerned with surface rights. If a CCS operator has acquired the disposal rights from the mineral owner, does the operator have an implied right to use as much of the surface as may be necessary for injection wells in order to be able to carry out its operation? Or, alternatively, must the operator obtain a separate consent from the surface owner? And what is the situation if that owner refuses to consent? Whatever the position may be at common law, the position seems to have been clarified in Alberta by a long-standing provision of the Surface Rights $A c{ }^{119}$ entitled "right of entry for conservation scheme."120

The general scheme of the $S R A$ is well known. Its general purpose is to do away with the implied right of entry that the mineral owner had as a matter of common law. In place of that common law right, s. 12 of the SRA contemplates that an oil and gas lessee no longer has a right of entry to the surface of any land unless and until it either enters into a separate surface rights agreement with the surface owner, or obtains a right of entry order from the Surface Rights Board (SRB). Upon making such an order, the SRB must also make a compensation award according to the statutory formula under s. 25 of the Act. Section 12 of the SRA is limited in scope. Thus, it deals with access for mineral purposes and access for linear developments - specifically: pipelines, transmission lines, and telephone lines. However, s. 13 extends this modified right of access scheme to the right of entry for conservation purposes:

13(1) When the surface of any land is required for the drilling or operating of a well, or for the necessary installations at or pipelines to or from a well, the Board may make an order granting right of entry in respect of the surface of the land where the well is to be used for the purpose of

(a) repressuring, recycling or pressure maintenance in a petroleum or natural gas field, pool or area,

(b) the storage or disposal of

See Alberta Energy, Information Letter 98-23: “Commercial Gas Storage in Alberta” (22 July 1998), online: Alberta Energy <http://inform.energy.gov.ab.ca/il/Documents/Published/IL-1998-23.pdf> stating that "[c]ommercial storage is considered market driven and is generally defined as storage that is not primarily related to optimization of recovery from its receiving reservoir" (at 1). In other words, "the storage does not involve ... enhanced hydrocarbon recovery through miscible floods; pressure maintenance; or gas cycling to maximize liquid extraction” (at 1). There are other reasons as well for thinking that this section is limited in scope: (1) it only deals with the situation as between the Crown and its lessees (it cannot deal with privately owned storage/disposal rights); and (2) it is, in any event, confined to the disposal of mineral substances which, as we have already suggested, does not include $\mathrm{CO}_{2}$, at least from an industrial source. R.S.A. 2000, c. S-24 [SRA].

120 Ibid., s. 13. Section 12(2) of the Interpretation Act, R.S.A. 2000, c. I- 8 confirms that section headers are not part of the enactment, but are inserted for convenience of reference only. 
(i) natural gas,

(ii) processed or treated natural gas, or

(iii) products of petroleum or natural gas,

(c) the storage and disposal of water or any other substance produced from or to be injected in an underground formation, or

(d) obtaining water for any operation mentioned in clause (a), (b) or (c).

(4) The provisions of this Act governing right of entry in respect of the surface of land for any purpose mentioned in section 12(1) apply insofar as they are applicable to an application or an order for right of entry in respect of the surface of land for any of the purposes mentioned in subsection (1) of this section. ${ }^{121}$

The section deals with access for both pipelines and wells where the well is to be drilled for any one of four purposes. The first purpose relates to classical conservation schemes. The second and third purposes both deal with storage or disposal wells, while the fourth purpose deals with a water well drilled in order to obtain water for a conservation scheme.

Both the second and the third purposes are potentially relevant here. The second purpose is more confined, since it deals with storage or disposal of natural gas, processed gas, and the products of petroleum or natural gas. While this might cover the situation of a well drilled to dispose of $\mathrm{CO}_{2}$ derived from a gas stream, it would not cover $\mathrm{CO}_{2}$ derived from an industrial source. The third purpose, however, is extraordinarily wide and covers "any ... substance ... to be injected in an underground formation."122

We conclude that this section is broad enough to allow the operator of a $\mathrm{CO}_{2}$ injection well and associated pipeline infrastructure to use the modified right of entry provisions of the SRA.

\section{REGULATORY ISSUES}

This Part of the article deals with a suite of regulatory issues that will arise in the context of the last two phases of the CCS cycle: approval of the disposal project, and associated wells and post-closure. ${ }^{123}$ Thus, this Part discusses the general regulatory scheme in place for approval of an injection well, followed by a discussion of the particular regulatory requirements for both EOR and AGD where they are of interest in relation to CCS. Finally, we note the lack of regulation surrounding long-term monitoring of abandoned wells and argue that such regulations are required for CCS. above. The NEB's report on the Souris Valley Pipeline (MH-1-98, supra note 18) provides a good analysis of the issues posed by $\mathrm{CO}_{2}$ pipelines. 


\section{A. Approval of $\mathrm{CO}_{2}$ Disposal/Storage Projects and Injection Wells}

The two analogies that best inform the required regulatory scheme for CCS in Alberta are EOR and AGD. Both are regulated in Alberta by the province's oil and gas regulator, the AEUB, under the terms of the Oil and Gas Conservation Act ${ }^{124}$ and the Oil and Gas Conservation Regulations. ${ }^{125}$ The OGCA does not deal with geological disposal beyond a number of generic sections. Most of the detail is found in the OGCA Regulations, and more specifically, in various AEUB directives.

Section 39 of the OGCA provides that no person may commence a scheme for "enhanced recovery," 126 or for "the storage or disposal of any fluid or other substance to an underground formation through a well," ${ }^{, 127}$ without the approval of the AEUB. The section is broad enough to give the AEUB jurisdiction over approval of any injection well, whether the "fluid or other substance" is $\mathrm{CO}_{2}$ derived from a natural gas stream or $\mathrm{CO}_{2}$ derived from an industrial source.

Section 39(1)(d) also requires the AEUB to forward any application for approval of storage/disposal schemes to the Minister of the Environment for that Minister's approval as it "affects matters of the environment." ${ }^{28}$ The AEUB is required to make any approval "subject to the same conditions imposed by the Minister of the Environment." ${ }^{\text {"129 }}$ It is possible that the Minister might require an environmental assessment of a CCS scheme under Division 1 of the EPEA before granting its approval. ${ }^{130}$

Several sections of the OGCA Regulations deal with EOR, gas storage, and disposal schemes, ${ }^{131}$ but the most relevant are those sections of Part 15 of the OGCA Regulations (“Certain Applications") which prescribe the form of applications for these types of projects. However, these provisions — s. 15.040 (enhanced recovery), s. 15.060 (gas processing and

Supra note 117. In addition to s. 39, the well licensing sections are also relevant. Thus a well includes a well drilled "for injection to an underground formation" (s.1(1)(eee)) and s. 11 provides that no person shall drill a well without a licence, while the familiar s. 16 provides that no person shall apply for a licence unless that person has the relevant rights for the purpose for which the well is being drilled neatly combining the property and regulatory aspects of the problem and emphasizing that both are necessary conditions precedent to drilling. Alta. Reg. 151/71 [OGCA Regulations].

OGCA, supra note 117, s. 39(1)(a).

Ibid., s. 39(1)(d).

Ibid., s. 39(2).

Ibid., s. 39(3).

Supra note 61. Under the EPEA, ss. 41, 44, any Director may refer a proposed activity for further assessment. Upon referral, the Environmental Impact Assessment (EIA) Director must require a proponent of a "mandatory activity" (s. 44(1)) to prepare an EIA but has somewhat more discretion with respect to other activities. Section 59(b) of the EPEA also contemplates categories of exempt activities which are prima facie (subject to an overriding ministerial discretion: s. 47) exempt from the application of the "environmental assessment process." The relevant regulation is the Environmental Assessment (Mandatory and Exempted Activities) Regulation, Alta. Reg. 111/93. That regulation exempts oil and gas wells but not injection or disposal wells. Mandatory activities that may have a $\mathrm{CO}_{2}$ capture process include oil sands upgrading and processing plants, thermal generating plants, and sour gas processing plants.

131 See also s. 14.200, which requires the continuous measurement of any substance injected by a well into an underground formation, as well as the abandonment provisions discussed in Part V.B, below. 
underground storage), and s. 15.070 (disposal of fluid or other substance) — do little more than refer the applicant to, and require compliance with, Directive $065 .{ }^{132}$

Directive 065 requires a classification of the injection well under AEUB Directive 051: Injection and Disposal Wells - Well Classifications, Completions, Logging, and Testing Requirements. ${ }^{133}$ Section 2.4 of Directive 051 classifies any well used for the injection of " $\mathrm{CO}_{2} \ldots$ or other gases used for storage or enhanced recovery [and] sour or acid gases for disposal, storage, or cycling operations” ${ }^{134}$ as a Class III well. Injection and disposal wells are classified by type of fluid injection in order to identify those wells that require increased levels of monitoring and surveillance. Directive 051 provides for the completion and logging requirements for each classification of well, including: (i) cementing and casing requirements; (ii) logging requirements to show hydraulic isolation; (iii) operating parameters; and (iv) other tests, such as daily annular and injectivity monitoring. ${ }^{135}$ Class III well completion and logging requirements are based on the presence of $\mathrm{H}_{2} \mathrm{~S}$ in the injection stream. Since $\mathrm{H}_{2} \mathrm{~S}$ is significantly more hazardous than $\mathrm{CO}_{2}$, the regulatory standards for completion and logging of a Class III disposal well ought also to be adequate for CCS.

Directive 065 requires applicants to notify those particular parties who may be affected by a resource scheme. ${ }^{136}$ The minimum requirements for notification are different for EOR and AGD schemes. For example, for new EOR schemes, the applicant must notify all well licensees for wells in the applied-for approval area and the area within a quarter section of the applied-for approval area. ${ }^{137}$ The applicant is not required to provide confirmation of nonobjection unless requested by the AEUB, and does not need to notify licensees of abandoned wells. ${ }^{138}$ In contrast, the requirement for a Class III disposal well includes notification of the unit operator, the approval holder of the scheme, all well licensees, all mineral lessees, and all mineral lessors. ${ }^{139}$ The area of the notification varies with the disposal site. If disposal of acid gas is into a depleted hydrocarbon pool, the notification area is the AEUB-designated pool; if into an aquifer, a radius of $1.6 \mathrm{~km}$ from the section containing the disposal well. The applicant is required to provide a statement as to the parties contacted respecting the application and confirmation of non-objection, or provide specific details regarding objections or concerns.

The AEUB's mandate for developing notification requirements is based on s. 26 of the Energy Resources Conservation Act, ${ }^{140}$ which requires that the AEUB ensure all persons potentially directly or adversely affected are given notice of an application and have a reasonable opportunity to make representations to them regarding the application. In principle, it seems that the notification requirements for CCS projects should draw on the

Supra note 77.

(March 1994) [Directive 051].

Ibid., s. 2.4.

Ibid. at 1.

Directive 065, supra note 77, Table 1.

Ibid., Table 1, s. 2.1.3.2.

Ibid., s. 2.1.3.2. Given that the highest risk for leakage with CCS is abandoned wells, we suggest that licensees of abandoned wells be transferred to the CCS prior to the start of a CCS project. See discussion in Part VI.A.3, below.

Ibid., Table 1, s. 4.2.2.

R.S.A. 2000, c. E-10. 
notification requirements developed for both EOR projects and for Class III disposal wells. Thus, CCS rules should incorporate the broader geographical notification requirements prescribed for EOR projects, ${ }^{141}$ as well as the depth of notification requirements prescribed for Class III disposal wells. The rules should, at a minimum, also require notification of licensees of abandoned wells. ${ }^{142}$ In short, the notification requirements for CCS need to be sensitive to the scale of CCS projects, both geographically and temporally, to ensure that all potentially directly and adversely affected persons will receive notice.

\section{ENHANCED OIL RECOVERY}

In addition to the general regulatory requirements for EOR or AGD, there are particular requirements for each that are relevant to CCS. A CCS project will likely be similar in terms of geographical scale to an EOR project, making EOR a useful analogy for approval of large geographical schemes. The AEUB has stated that its objective in regulating EOR schemes is to ensure that hydrocarbon recovery is optimized. In meeting this objective, the AEUB must also ensure that scheme operations are conducted in a safe manner that is in the best interest of the public, protects the environment, and is equitable to other well licensees. ${ }^{143}$ Many of the requirements for AEUB approval of an EOR scheme are not relevant to CCS due to the different objectives; however, one requirement is relevant. The AEUB requires that that the proposed approval area for an EOR scheme must reflect the area that will be effectively swept by the injection wells, and the approval area must not extend beyond the AEUB's Pool Order boundary for the subject pool. ${ }^{144}$ This requirement has application to CCS. At a minimum, a CCS project would need to encompass a similar concept; however, the focus would not be on whether the swept area is within the Pool Order boundary, but rather whether the sequestration area or plume capture area (a concept similar to the swept area) is within Pool Order boundary. ${ }^{145}$

As we have already noted, one of the drawbacks to basing CCS regulation on existing rules for EOR projects is that they have different objectives. CCS projects aim for permanent disposal, while EOR projects aim for enhancing recovery of hydrocarbons - in such cases, $\mathrm{CO}_{2}$ injection is simply a means to that end. The dissonance between these two objectives is illustrated by those provisions of Directive 065 which require that gases produced from an EOR scheme be conserved in accordance with AEUB Directive 060: Upstream Petroleum

See infra note 145 for a discussion of the problems associated with using fixed radius areas with CCS. See supra note 138 and accompanying text for a discussion regarding transfer of licences.

Directive 065, supra note 77, s. 2.1.2.

Ibid., s. 2.1.2.1.

The concept of Pool Order boundary may need to be changed for CCS in the event that the sequestration area is not equivalent to an existing pool. In the U.S., this same concept is called the "Area of Review," or "AOR," and is typically a fixed radius around a well designed to protect underground sources of drinking water. One study looked at the adequacy of the standard AOR in the Gulf Coast area of Texas in the context of the expected plume behaviour of CCS. The conclusion was that a fixed radius AOR in a CCS project is inadequate as the $\mathrm{CO}_{2}$ trap is typically elongated and includes a vertical dimension in addition to the two customary lateral dimensions: Jean-Philippe Nicot et al., "Area of Review: How large is large enough for carbon storage?” (2006) Bureau of Economic Geology, University of Texas at Austin, online: Bureau of Economic Geology <http://www.beg.utexas.edu/environqlty/co2seq/ pubs_presentations/UIC_Nicot.pdf>. 
Industry Flaring, Incinerating, and Venting. ${ }^{146}$ Directive 060 requires an operator to conserve gas, if it is economic to do so. ${ }^{147}$ The directive primarily deals with the conservation of solution gas, but it also addresses other produced gases and in particular states that: "inert gases such as nitrogen and carbon dioxide $\left(\mathrm{CO}_{2}\right)$ from upstream petroleum industry equipment or produced from wells ... can be vented to atmosphere.”148 Clearly, such a provision is entirely inconsistent with the goals and objectives of a CCS project.

Very few EOR applications have triggered a public hearing or produced formal reasons for decision from the AEUB. These few decisions tend to focus on economic or technical considerations $^{149}$ or deal with the possible implications of waterflood schemes on groundwater and surface water. ${ }^{150}$

\section{ACID GAS DISPOSAL}

By contrast with an EOR application, an application for an acid gas disposal scheme must address the need for permanent disposal. ${ }^{151}$ The AEUB states that an application for acid gas disposal will likely be approved if the AEUB is satisfied that:

- the disposal will not impact hydrocarbon recovery,

- the disposal fluid will be confined to the injection formation,

- the offset owners within $1.6 \mathrm{~km}$ of the disposal well(s) have been consulted and have no objections or concerns to the disposal scheme, and

- the applicant has the right to dispose into the requested formation. ${ }^{152}$

In order to satisfy itself as to each of these matters, the AEUB's Directive 065 requires an applicant for AGD approval to provide information on containment of injected substances, reservoir characteristics, hydraulic isolation, equity, and safety. ${ }^{153}$

Under the heading of "Containment," the AEUB expects the applicant to be able to show that the injected fluids will be contained "within a defined area and geologic horizon, to ensure that there [will be] no migration to hydrocarbon-bearing zones or groundwaters."154

(16 November 2006) [Directive 060]. This is a new directive that came into effect on 31 January 2007. See also Directive 065, supra note 77, s. 2.1.3.3(B)(17).

Directive 060, ibid., s. 2.8: "If conservation is determined to be economic by any method using the economic decision tree process, the gas must be conserved.” The conservation of $\mathrm{CO}_{2}$ in a CCS project may not be economic under the Directive.

Ibid., s. 8.5.

See e.g. ERCB, Decision 73-6: Ndp Exploration Canada Ltd. Application for Concurrent Production of Oil Accumulation and Gas Cap with Gas Cap Cycling, Bonnie Glen D-3A Pool.

See e.g. AEUB, Decision 2002-032: Case Resources Inc. Enhanced Oil Recovery Scheme, Oil Well Effluent Pipeline and Water Pipelines, Carrot Creek Field (26 March 2002). In this decision the waterflood involved the use of fresh water.

This section draws upon material in Bankes \& Poschwatta, supra note 10.

Directive 065, supra note 77, s. 4.1.3.

In addition to the text of the Directives there has been some discussion of the AEUB's regulatory requirements in the technical literature. See in particular H.L. Longworth, G.C. Dunn \& M. Semchuk, "Underground Disposal of Acid Gas in Alberta, Canada: Regulatory Concerns and Case Histories" in Proceedings: Gas Technology Symposium, 28 April - 1 May 1996, Calgary Alberta, Canada (Richardson, Texas: Society of Petroleum Engineers, 1996) 181.

Directive 065, supra note 77, s. 4.2.2. 
Hence, the applicant will be expected to provide a complete and accurate drilling history of offsetting wells within several kilometres, as well as information on the permeability of the cap rock and any fracturing. The applicant will also be expected to identify folding and faulting and comment on how this relates to seismic risk — both the effect of seismic activity on the integrity of the project, and the effect of disposal schemes on (increased) seismic activity. Under the heading of "Reservoir Characteristics," 155 the applicant will need to describe and analyze the native reservoir, the composition of the waste stream and phase behaviour, as well as migration calculations and proposed bottom hole injection pressures. Board approvals will be limited to 90 percent of formation fracture pressures. The AEUB will expect an assessment of the effect of the acid gas on the target zones. Under the heading of "Hydraulic Isolation," 156 the AEUB expects the applicant to demonstrate that all potable water-bearing zones as well as hydrocarbon-bearing zones are hydraulically isolated from the proposed injection wells by cement and/or casing with all injection occurring through tubing appropriately isolated from the casing by packer, with casing integrity confirmed by an inspection log.

Many of the "safety" concerns that apply to AGD projects are the same as those that apply to all sour gas wells and facilities including pipelines. These include a requirement for the development of an emergency response plan (ERP), including an emergency planning zone that is the area of land that may be impacted by an $\mathrm{H}_{2} \mathrm{~S}$ release and may include the processing plant, the injection well, and the connecting pipeline. The AEUB expects to see evidence of broad public consultation on both the ERP and all other matters related to the proposed project. Finally, under "equity” issues the AEUB expects the applicant to provide evidence that all offsetting mineral rights owners have been contacted, as well as details of outstanding objections or concerns. ${ }^{157}$

Perhaps surprisingly, very few AGD applications have triggered a public hearing and formal reasons for decision from the AEUB approving a project. This suggests that in most cases the applicant has been able to allay possible public concerns through its consultation activities. The following paragraphs discuss some of the issues that have been raised in the few published AEUB decisions that relate to AGD.

The concern that seems to have been raised most frequently is the potential for flaring (and therefore acid gas emissions) in the event that the injection facility is shut down for any reason. Past decisions of the AEUB dealt with this issue somewhat inconsistently. In some cases, the AEUB seems to have been content with a commitment from the operator to reduce throughput, ${ }^{158}$ while in other cases, the AEUB has accepted or required an undertaking from

Ibid.

Ibid., referring to Directive 051, supra note 133.

Ibid., under the heading of "Notification — Equity and Safety."

AEUB, Decision 2001-43: Duke Energy Midstream Services Canada Ltd., Application to Modify an Existing Sour Gas Plant and Amend an Existing Acid Gas Disposal Scheme, Pouce Coupe Field (23 May 2001) [Decision 2001-43]. Section 5.1 of the decision refers to Duke's commitment to the effect that if acid gas injection problems could not be resolved within two hours Duke would reduce its inlet rates to one-third. In s. 5.3, the AEUB expressed some concerns about this but seemed content to monitor the situation. 
the operator that it will shut down operations in such an event, thereby confining any flaring to those small volumes necessary to depressure and render equipment safe. ${ }^{159}$

In one case, an intervener raised concerns as to containment of the acid gas at the disposal site and was especially concerned that there was perhaps an unrecorded abandoned well that might affect the integrity of the disposal scheme. ${ }^{160}$ The AEUB assessed these concerns, but satisfied itself that: (1) proposed bottomhole pressures would be significantly lower than fracture pressures; (2) the existing data confirmed the hydraulic isolation of the target formation; (3) the proponent would monitor producing wells for any increase in $\mathrm{H}_{2} \mathrm{~S}$ levels that might indicate problems with acid gas containment; and (4) a review of Board records, interviews with long-time residents, as well as the "checks and balances" in the energy sector made it "extremely unlikely for a company to have drilled an unlicensed well in the 1970s.”"161

Other concerns that have been raised include concerns as to whether other operators will know of the existence of an AGD project when carrying out operations many years into the future, and concerns as to contamination of groundwater sources. ${ }^{162}$ Another general concern relates to the length of acid gas pipeline, a concern that the AEUB has generally dealt with by requiring the close co-location of processing and injection facilities. ${ }^{163}$

While the AGD regulatory model represents a compelling analogy to be applied to CCS projects, it will require some modification to account, in particular, for the much larger scale of CCS projects. It is anticipated that CCS schemes will be approximately 10 to 100 times larger than current acid gas disposal schemes. ${ }^{164}$ Similarly, it is unrealistic to maintain the emphasis that Directive 065 places on structural trapping. While this may be appropriate in the case of depleted oil and gas reservoirs, it is less applicable in the case of injection into a saline formation where the plume of acid gas is no longer physically contained as it is in reservoirs. Thus, instead of emphasizing containment, there will be a need to develop regulations and guidance on plume spread and migration, and on associated monitoring requirements. Given that transparency is a concern, it may also be important to provide for the explicit treatment of CCS issues in the statute and regulations, rather than deferring everything to the much more discretionary guidelines. Finally, a CCS regulatory scheme will need to make explicit provision for monitoring and verification of the behaviour of the $\mathrm{CO}_{2}$ plume both during and after active injection. We expand on this point in the following section.

AEUB, Decision 99-31: Northrock Resources, Application to Construct and Operate a Sour Gas Processing Facility, Associated Pipelines, Wellsite Facilities, and an Acid Gas Disposal Scheme, Pembina Field (23 December 1999) [Decision 99-31]. See also AEUB, Decision 2000-42: Burlington Resources Canada Energy Ltd., Application to Modify an Existing Sweet Gas Processing Plant to Include Sour Gas Processing, Associated Pipelines, Acid Gas Disposal Well, and Acid Gas Disposal Scheme, Pembina Area (23 June 2000), s. 5.3 [Decision 2000-42]. Decision 2001-43, supra note 158.

Ibid., s. 6.3.

Decision 2000-42, supra note 159, s. 5.3.

See Decision 99-31, supra note 159, s. 8.3.1, and noting in that case that the $\mathrm{H}_{2} \mathrm{~S}$ pipeline would be installed above grade in a utilidor with $\mathrm{H}_{2} \mathrm{~S}$ detection equipment every 30 metres.

Bachu \& Haug, supra note 29. 


\section{B. Regulation of the Abandonment OR Post-Injection Phase of a CCS Project}

At some point in any CCS project, the active injection phase will come to an end. At that point, the operator will seek to abandon the injection facilities, subject, of course, to the need for long-term monitoring of the behaviour of the $\mathrm{CO}_{2}$ plume and monitoring for the integrity of the disposal operation. How should these activities be regulated? In order to answer that question we can look at the regulatory framework that applies to conventional wells and to injection wells used in AGD schemes.

The general regulatory scheme in Alberta is based on a distinction between subsurface and surface abandonment, and surface reclamation. ${ }^{165}$ Pursuant to a Memorandum of Understanding between the AEUB and Alberta Environment, ${ }^{166}$ the AEUB is generally responsible for ensuring the proper suspension and abandonment of wells (under the OGCA), while Alberta Environment is responsible for surface land reclamation activities and any required decontamination (or remediation) under the EPEA. ${ }^{167}$ This article focuses on the responsibilities of the AEUB.

The Memorandum of Understanding defines "abandonment" as the permanent dismantlement of a licensed facility so that it is permanently incapable of its licensed use. ${ }^{168}$ Abandonment includes: "leaving downhole or subsurface structures in a permanently safe and stable condition ...; the removal of associated equipment and structures; the removal of all produced liquids; and the removal and appropriate disposal of structural concrete.”169

All abandonment operations are to be conducted according to AEUB Directive 020: Well Abandonment Guide. ${ }^{170}$ The objective of proper well abandonment is to cover, with cement, all non-saline ground water and to isolate or cover all porous zones. ${ }^{171}$ The Directive applies to all wells, including those involved in EOR or AGD.

Under Directive 020, the licensee must determine whether the planned abandonment operation is routine or non-routine. If an abandonment operation is routine, it does not require AEUB approval prior to work starting. Non-routine operations do require prior

Alberta's scheme is analyzed in Nickie Vlavianos, "Liability for Suspension/Discontinuation, Abandonment and Reclamation in Alberta: An Update” (2002) 39 Alta. L. Rev. 864. See also her LL.M. thesis, "Liability for Well Abandonment, Reclamation, Release of Substances and Contaminated Sites in Alberta: Does the Polluter or Beneficiary Pay?” Faculty of Law, University of Calgary, online: Library and Archives Canada <http://www.collectionscanada.ca/obj/s4/f2/dsk2/ftp01/MQ55188.pdf>. Memorandum of Understanding Between AEP and EUB on Suspension, Abandonment, Decontamination, and Surface Land Reclamation of Upstream Oil and Gas Facilities, reproduced in AEUB, Informational Letter IL 98-02: "Suspension, Abandonment, Decontamination and Surface Land Reclamation of Upstream Oil and Gas Facilities” (26 March 1998), online: ERCB <http://www.ercb.ca/ docs/ils/ils/pdf/il98-02.PDF> [Memorandum of Understanding].

Supra note 61.

Supra note 166 at 3 . This is consistent with the definition of abandonment in s. 1(1)(a) of the OGCA, supra note 117.

Memorandum of Understanding, ibid.

(7 December 2007) [Directive 020]; OGCA Regulations, supra note 125, s. 3.013.

Directive 020, ibid., s. 2. 
approval. ${ }^{172}$ The specific requirements for downhole abandonment vary depending on the type of well being abandoned, the well's geographic location, the impact of the well on any oil sands zones, and any wellbore problems.

Prior to beginning any surface abandonment, a licensee must inform all affected parties, including the landowner and/or occupant of the land. A licensee is also required to complete certain tests on the well prior to beginning any routine or approved non-routine surface abandonment operations such as fluid level testing, surface casing vent flow testing, and gas migration testing. Some areas also require a site inspection by the AEUB prior to beginning surface abandonment. Surface abandonment may begin after testing shows there are no wellbore problems. Normally, surface abandonment must be completed within 12 months of downhole abandonment.

The directive requires that completion reports and plug logs must be submitted to the AEUB. ${ }^{173}$ A licensee must keep all test results and abandonment details. If the licence for an abandoned well is transferred, the new licensee assumes all responsibility for monitoring the abandoned well. ${ }^{174}$

Much of this regulatory scheme can likely be directly applied to the abandonment phase of a CCS project. But there is one significant gap: Directive 020 does not require ongoing monitoring or verification of a well after surface abandonment, while monitoring and verification will certainly be required for a CCS project to ensure that the project remains both operationally safe and effective over the long term. ${ }^{175} \mathrm{CCS}$ abandonment must consider both proper well-by-well abandonment and overall project abandonment.

A CCS project requires verification in order to assess the amount of $\mathrm{CO}_{2}$ that is stored underground, to assess the behavior of the $\mathrm{CO}_{2}$ plume, and to assess how much, if any, $\mathrm{CO}_{2}$ is leaking back into the atmosphere. Effective monitoring and verification are a key component to minimizing the risks associated with CCS by providing a trigger for remedial action. ${ }^{176}$ They will also play a key role in achieving public acceptance of CCS as a means of reducing GHG emissions. Most long-term monitoring can be accomplished using the same technologies currently used in industry. Many of these technologies are used in the injection phase and would need to continue post-injection.

Some examples of non-routine abandonment operations are: (i) the planned abandonment of a well that has a wellbore problem; (ii) a re-abandonment of a well; (iii) a planned surface abandonment of a well with pressure remaining at surface; (iv) a planned surface abandonment of a well where cement does not cover all non-saline groundwater zones; (v) the planned use of cement plugs in a well in a manner that does not meet the requirements stated in the guide; (vi) the planned use of a bridge plug inside the surface casing; (vii) the planned use of any type of plugging device that will be set more than 15 metres above the completion interval; and (viii) the planned removal of un-cemented casing from the well in a manner that does not meet the requirements stated in the Guide. 
There are currently no established monitoring protocols for CCS projects. ${ }^{177}$ Given that geological storage/disposal of $\mathrm{CO}_{2}$ may persist over many millions of years, the questions surrounding long-term monitoring are complex. The Australian Guiding Principles suggest that a regulatory framework for monitoring and verification in CCS should be able to deliver mechanisms to:

- $\quad$ establish data on the atmospheric, near-surface and sub-surface environment;

- monitor the project environment to manage and mitigate health, safety and environment risks;

- ensure certain standards for health, safety and environment and subsurface behaviour of the CCS stream are met before responsibility for the project is transferred from private to public interests (if deemed appropriate); and

- develop and manage a monitoring and verification plan to cover all stages of the CCS project including post-closure. $^{178}$

There is a need for regulations to address long-term monitoring in a way that is both costeffective and effective at detecting leaks or unexplained movement of the plume.

The length of time for which monitoring and verification is required is a subject of much discussion. While there are some calls for extensive and on-going monitoring, a more practical solution appears to be that long-term monitoring cease once it has been demonstrated that the plume of $\mathrm{CO}_{2}$ is no longer moving. ${ }^{179}$

In conclusion, a $\mathrm{CO}_{2}$ injection operation is already subject to regulation by the AEUB under the OGCA and the OGCA Regulations. However, while these regulations have been designed to cover analogous operations such as AGD and EOR, they require some adjustment to deal with CCS. In particular, we think that it is important that the OGCA, the regulations, and Directive 065 deal explicitly with CCS issues. While the existing provisions might be used as a model, they require amendment to deal with the scale issues associated with CCS, and to require long-term monitoring and verification of the fate of the $\mathrm{CO}_{2}$ plume. 


\section{LIABILITY ISSUES}

There are at least two distinct types of liability issues associated with CCS projects. ${ }^{180}$

The first type of liability is the potential liability of the operator (or another party) to those who suffer harm either as a result of slow leakage (the operator of a conventional oil or gas reservoir may suffer economic loss as a result of leakage into its reservoir, or acidification of the vadose zone might reduce crop yields or impair habitat values or harm burrowing animals), or as a result of a more catastrophic event (loss of life as a result of $\mathrm{CO}_{2}$ accumulating in high densities in low-lying areas). Closely associated with this is the need to ensure that the operator (or other party) has adequate funds to take necessary remedial action (re-completing a well that has lost its integrity, etc). We shall refer to this set of liability issues under the heading "legal liability issues," the first sub-group of issues as general (or third-party) legal liability issues, and to the second sub-group as remedial liability issues.

A second type of liability is the liability that may accrue from an atmospheric release of $\mathrm{CO}_{2}$ within a national or international greenhouse gas reduction regime. Thus, a release from a $\mathrm{CO}_{2}$ disposal project will be treated as an emission for the purposes of the Kyoto Protocol which will be added to the national account. It is also possible that the emission may trigger a liability under domestic implementing legislation (when enacted), perhaps requiring the person responsible (the operator or another party) to acquire credits to offset the emissions. We shall refer to this set of issues as the CCS accounting issues.

\section{A. LEgAL LiABILITY IsSUES}

In discussing the legal liability issues, most of the literature distinguishes between the first three phases of the CCS cycle and the fourth, or post-closure, phase. It is generally assumed that prior to the post-closure phase, any liability for harm caused should be covered by the liability rules of the laws of general application on the grounds that there are no special risks or other unusual consideration associated with these activities. ${ }^{181}$

This section of the article deals first with the general legal liability issues and then discusses the remedial liability issues in the context of each of conventional oil and gas operations and acid gas disposal schemes. In Alberta, general legal liability is largely a matter of common law, while remedial liability issues are largely covered by statute. In each case we emphasize that the same rules apply to both acid gas disposal schemes and conventional oil and gas operations. The section concludes by discussing a more normative question, that is: What sort of liability regime should we put in place for CCS schemes? Our overall conclusion is that the general approach of the current liability regime can be applied with some minor modifications to CCS operations. However, we also consider two other 
liability regimes in order to identify additional design elements that might be taken into account in designing a CCS liability regime.

\section{GENERAL LEGAL LIABILITY}

In Alberta, losses suffered as a result of an oil spill or similar incident may be recovered (if at all) by a tort action based in negligence and/or nuisance ${ }^{182}$ or through strict liability on the basis of trespass or the rule in Rylands v. Fletcher. ${ }^{183}$ The OGCA does not create a private cause of action or a special liability regime for those who suffer harm as a result of a release. Other jurisdictions do provide special liability rules for release events, including blow-outs during drilling operations. ${ }^{184}$ The same principles apply to both AGD operations and to conventional oil and gas operations. The likely defendant would be the project operator, but others (including the owner(s) of the $\mathrm{CO}_{2}$ stream, and the owner and occupier of land) might also be joined as defendants on principles of joint and several liability. ${ }^{185}$ The operator might seek to shift this liability to others (owners/suppliers of the $\mathrm{CO}_{2}$ stream) through various contractual indemnity arrangements. For example, the operator might seek to have the owners of the waste stream (perhaps the owner of the coal-fired generating plant ${ }^{186}$ ) indemnify it against both harm or damage that it may suffer directly, or as a result of actions brought by third parties. ${ }^{187}$ Alternatively, the suppliers of the $\mathrm{CO}_{2}$ might reasonably argue that the operator of the disposal project should indemnify them once the operator has taken custody and control of the $\mathrm{CO}_{2}$. They will argue that the operator's charges should reflect this assumption of risk, leading the operator to self-insure or acquire insurance on the market. This second allocation of risk seems more appropriate (because it provides the relevant incentive to the operator to take all reasonable and prudent measures to prevent escapes) and, therefore, more likely to be reflected in the private contractual relations between the parties.

\section{REMEDIAL LIABILITY}

By contrast with the general legal liability rules, the remedial liability rules are governed by statute. These rules allocate liability for two types of situations: (1) liability for proper abandonment in the event of a default by a licensee; and (2) provisions for cost recovery in the event of a failure to comply with an AEUB order relating to a spill, blow-out, or similar incident. As to the first situation, the OGCA contemplates that all suspension and

Phillips v. California Standard Co. (1960), 31 W.W.R. 331 (Alta. S.C. (A.D.)); Penn West Petroleum Ltd v. Koch Oil Co. (1994), 148 A.R. 196 (Q.B.); Kennedy et al., "Liability for Waterflood Operations," supra note 94.

(1868) L.R. 3 H.L. 330.

See e.g. Canada Oil and Gas Operations Act, R.S.C. 1985, c. O-7, s. 26 which imposes strict liability on the operator in favour of those who suffer losses as a result of a spill.

And for a recent discussion of these issues in an oil and gas context, see Freyberg v. Fletcher Challenge Oil and Gas Inc., 2007 ABQB 353, [2007] 10 W.W.R. 133.

Ownership of the waste stream will no doubt vary with the type of capture facility and injection operation. We can expect ownership issues to be precisely delineated where the $\mathrm{CO}_{2}$ has a commodity value (e.g. where it is being used in an EOR scheme). It may be less well delineated where it is a waste stream.

The Alberta statutory scheme for injection wells contemplates that a person who exercises an injection right "shall indemnify the Crown in right of Alberta for loss or damage suffered by the Crown in respect of any claims or demands made by reason of anything done by that person or any other person on that person's behalf in the exercise or purported exercise of that right” (MMA, supra note 68, s. 56(2)(a)). 
abandonment activities are the responsibility of the licensee and/or the working interest owners in the well or facility. ${ }^{188}$ In default thereof, the AEUB may authorize any person to carry out those operations for the account of the licensee and other working interest owners in the well or facility. In the event of default in covering these suspension, abandonment, and related reclamation costs, these costs can be recovered from the "Orphan Fund"; the Fund is financed by a levy on the industry. ${ }^{189}$ The OGCA does not contemplate that abandonment will serve to transfer any continuing liability to the government. In fact, s. 29 states that: "Abandonment of a well or facility does not relieve the licensee, approval holder or working interest participant from responsibility for the control or further abandonment of the well or facility or from the responsibility for the costs of doing that work." ${ }^{\circledR 90}$ In general terms, once a well has been abandoned and a reclamation certificate issued, a licensee is no longer able to transfer the licence for that well. ${ }^{191}$

As to the second category of events, various sections of the OGCA (ss. 100, 104-105) contemplate that the AEUB may order the licensee of the well or other facility to take necessary action, and in default thereof authorize others to do so. In such a case, the AEUB may recover these costs from the licensee and working interest owners in the well or other facility; however, in this case there is no secondary liability on the Orphan Fund, except to the extent that some of these costs might also be characterized as (re-) abandonment costs. As with the general legal liability rules, these remedial liability rules apply equally to conventional oil and gas operations and to AGD schemes. ${ }^{192}$

In sum, the general liability regime provides that the licensee and those with an interest in the well or facility have the primary liability for suspension, abandonment, and

OGCA, supra note 117 , ss. $27,30$.

The Fund is established by Part 11 of the OGCA, ibid., ss. 68-77. The Orphan Fund levy is payable by licensees of wells and other facilities. The amount of the levy is prescribed by Part 16.5 of the OGCA Regulations, supra note 125, and the relevant Board policy document is AEUB, Directive 006: Licensee Liability Rating (LLR) Program and Licence Transfer Process (20 September 2005) [Directive 006]. OGCA, ibid., s. 29.

There are some exceptions to this general statement. For example, a licence for an abandoned well that is not included within the LLR Program may be transferred: Directive 006, supra note 189.

Special rules do apply to oilfield waste management facilities: see Part 16.6 of the OGCA Regulations, supra note 125 . These special rules require payment of security which may be used for "the suspension, abandonment, site decontamination or surface land reclamation, or any combination of them, of an oilfield waste management facility" (s. 16.644). The security is payable before construction or operation of the facility commences. For an interesting AEUB decision that deals with the asset basis on which the security deposit is to be calculated, see AEUB, Decision 2006-082: 3R Sand Limited, Application to Amend Waste Approval WM068, Seven Persons Area (8 August 2006). The decision is of broader interest here insofar as the applicant was arguing that the AEUB's jurisdiction was confined to oilfield waste facilities and that part of the facilities should not be so classified insofar as the facility was able to sell cleaned frac sand as a commodity and that therefore the sand could not be a waste. The Board held that all of the facilities should be included in the calculation and commented more broadly that (at s. 5.3):

It would be unworkable if the EUB's jurisdiction over an oilfield waste facility were engaged or disengaged depending on the commercial demand from time to time of the processed intermediate or end product. The uncertainty of what was being regulated and when the regulation was effective would undermine the purpose of the current waste management legislation.

There are some obvious analogies between this discussion and discussions as to the characterization of $\mathrm{CO}_{2}$ : see Part III.C, above. 
reclamation. That liability is a continuing liability. The industry fund offers a secondary source of funds to cover that liability, but this statutory scheme is limited to these types of costs. The statutory scheme does not create a special liability regime to cover harms suffered by others as a result of a release. This scheme applies to all wells including AGD wells.

\section{APPLICATION TO CCS}

These, then, are the default rules that we might expect to apply to a CCS storage/disposal operation in Alberta. However, some of the CCS literature argues that it is necessary to modify these default rules during the post-closure period on the grounds that they will prove inadequate over the long-term duration of a disposal project. Thus, many commentators assert or assume that the point at which we move from the injection phase (including a period to satisfy a regulator that the project is stable and performing as anticipated — for example, the $\mathrm{CO}_{2}$ is dissolving in the aquifer at anticipated rates and the $\mathrm{CO}_{2}$ is migrating no more than anticipated) to the post-closure phase, we will need to shift liability for the project from the private operator to the public. ${ }^{193}$ Commentators justify this liability shift on pragmatic (corporations do not have a long enough "life") and philosophical grounds (this "reflects the fundamentally public nature of the risks and benefits of this type of storage”194). In particular, the literature emphasizes that as time passes, it is increasingly unlikely that the defendant will still be an extant or viable entity capable of discharging its liabilities. Should this happen, those who suffer harm will not be compensated (in other words, the site will be orphaned and the costs will lie where they fall) and where a project requires remediation (for example, reabandonment of an injection well), the cost of carrying out that activity will likely fall on government where the operator no longer exists.

As a result of these concerns, some have suggested that governments should "accept postclosure responsibility for the stored CCS stream once the regulator has approved site closure." ${ }^{\text {"95 }}$ Australian governments seem to favour this approach, and the U.S. Interstate Compact Commission has noted that "Given the long time frames ... innovative solutions to protect against orphaned sites will need to be developed.”196 The IOGCC suggests that government will need to provide the ultimate assurance. ${ }^{197}$

See e.g. James McLaren \& James Fahey, "Key Legal and Regulatory Considerations for the Geosequestration of Carbon Dioxide in Australia” (2005) 24 ARELJ 45 at 71-72; David Keith \& Malcolm Wilson, "Developing Recommendations for the Management of Geological Storage of $\mathrm{CO}_{2}$ in Canada," Prepared for Environment Canada, Saskatchewan Industry and Resources, Alberta Environment, and British Columbia Energy Mines (November 2002), online: University of Calgary $<$ http://www.ucalgary.ca/ keith/papers/61.Keith.2002.CanadianCO2Protocol.e.pdf >. Perhaps the most concrete evidence of adoption of this approach is draft state legislation in Texas and Illinois designed to offer the operator of the proposed FutureGen project an indemnity from post closure liabilities. For Illinois, see U.S., H.B. 1777, Clean Coal FutureGen for Illinois Act, 95th Gen. Assem., Reg. Sess., Ill., 2007.

Keith \& Wilson, ibid. at 9.

Australian Guiding Principles, supra note 9 at 42-43. This proposal emerged from the consultation exercise carried out as part of developing the guiding principles but was accepted in the final document (at 44), although it is not entirely clear if the operator retains primary liability to the extent that it is (a) negligent and (b) still extant.

IOGCC Report, supra note 16 at 56.

Ibid. at 54-56. 
The Alberta experience suggests that we should be cautious before assuming the need to create a special liability regime for dealing with the post-closure phase of a CCS project. The Alberta regulations suggest that it may be possible to require that the CCS industry itself ${ }^{198}$ provide the additional security needed to assure the public that resources will be available to take the necessary remedial action in the event of a leak or catastrophic release from a storage/disposal reservoir. The Alberta regulations also suggest that this additional security might be confined to the costs actually incurred in containing any release, as well as to any necessary re-abandonment operations, and that it is unnecessary to create a fund to deal with a broader range of possible compensation claims. By the same token, however, the coverage could be extended to provide a fund to compensate third parties who suffer loss as a result of a release event, although it would probably be necessary to also create a private cause of action to make such a scheme effective. ${ }^{199}$

One difficulty that would exist if we were to apply the current liability scheme relates to the restriction on the transfer of licences of abandoned wells, as discussed in Part VI.A.2, above. In non-CCS situations, this restriction on transfer is necessary in order to assure proper allocation of liability; however, it is hardly appropriate for a CCS scheme. For example, suppose a CCS scheme involved an area that contained several properly abandoned wells that had been issued reclamation certificates. Under the present liability regime, if one of the abandoned wells leaked as a result of repressurization from the injection of $\mathrm{CO}_{2}$ in a CCS operation, the licensee for the abandoned well would be liable for remediation - not the CCS operator. ${ }^{200}$ The licence holder for the abandoned well would then be forced to seek indemnity through the courts. Such a system of allocating liability would be ineffective and inefficient. We suggest that the operator of a CCS scheme should be required, as a term and condition of project approval, to take an assignment of licences for all abandoned wells within the CCS approval area, and that Directive $006^{201}$ be modified to allow for transfer of all such wells.

Should it be necessary to go beyond these suggested modifications to the existing system and to think about a more radical re-structuring of a liability scheme, we have identified two possible schemes that may provide useful analogies. The first draws upon the post-closure

This might raise a nice question as to which parties should contribute to a levy: Should it be those who provide the $\mathrm{CO}_{2}$ or the operator? Should there be a separate fund for CCS projects or a single fund? Suppose, for example, that in the same jurisdiction some CCS projects dispose into aquifers and some into depleted reservoirs as part of an EOR project. Under the Alberta Orphan Fund, the general rule is that all facilities, wells, and unreclaimed sites constitute a single class for the purposes of determining the levy, but there is at least one exception for this with respect to the Large Facility Management Program. This Program applies to designated large facilities such as sulphur recovery plants, stand-alone straddle plants, and in situ oil sands central processing facilities. See AEUB, Directive 024: Large Facility Liability Management Program (September 2005) and especially at s. 8.5, noting that "[t]he deemed liability of facilities within the LFP will be tracked separately from the deemed liability ... within the LLR Program. An orphan levy required under the LFP will be based solely on the deemed liability of facilities included within the LFP.” This idea of a segregated fund may be a useful model for designing a CCS fund. storage/disposal but not for acid gas disposal. Both have the same aim: long-term safe storage. However, an $\mathrm{H}_{2} \mathrm{~S}$ release would likely prove far more hazardous. 
liability rules recently developed by Saskatchewan to deal with its mining sector (including uranium mines), and the second draws upon the international liability regime for tanker spills. We summarize each of those schemes in the following sections.

\section{Post-ClOSURE Liability FOR Mining Operations (SASKATCHEWAN)}

Saskatchewan has a mature mining industry, including several uranium mines located on Crown lands. ${ }^{202}$ The regulatory framework for mining requires that planning and approval for decommissioning and reclamation occur during the initial stages of development. ${ }^{203}$ The operator of a mine must conduct a detailed review of the decommissioning plan and the financial assurance instrument at least once every five years, whenever requested to do so by the Minister, or within the 12 months preceding the permanent closure of such facility. ${ }^{204}$ An operator who wishes to permanently close a mine must: (a) advise the Minister in writing at least 60 days before commencing the permanent closure; and (b) implement the approved decommissioning and reclamation plan according to the timeframe set out in the plan. ${ }^{205}$

Once the site decommissioning and reclamation plan is completed, the site enters a transition-monitoring phase during which the mining company must demonstrate, at its own expense, that the site is physically and chemically stable. The operator must maintain financial assurances sufficient to cover the cost of the remaining obligations (as outlined in the decommissioning and reclamation plan) for the balance of the transition period, and must maintain a contingency amount for any unexpected problems. The province will inspect the site and review the mining company's site monitoring and maintenance. During the transition-monitoring phase, the mining company is liable for human health and safety concerns as well as any impacts on the environment. ${ }^{206}$

When the transition-monitoring phase is completed to the satisfaction of the province, the operator may apply for a release from the requirements in the decommissioning and reclamation plan. ${ }^{207} \mathrm{~A}$ closed site can be entered into the Institutional Control Program, wherein the operator is released from further monitoring and maintenance responsibilities and is released from its surface lease. ${ }^{208}$ Entry into the "Institutional Control Program" transfers custodial responsibility to the province, which would then manage those mine sites located on Crown land. Group (August 2005), online: Government of Saskatchewan <http://www.ir.gov.sk.ca/Default.aspx? $\mathrm{DN}=4819,3630,3385,2936$,Documents $>$ is a key source that outlines the long-term management of decommissioned mine/mill properties located on Crown land. a conceptual decommissioning and reclamation plan in its environmental impact statement: ibid. at 11. Project approval is received pursuant to the Environmental Assessment Act, S.S. 1979-80, c. E-10.1. The Mineral Industry Environmental Protection Regulations, 1996, R.R.S. 2000, E-10.2, Reg. 7 [MIEP Regulations] governs operations, decommissioning, and reclamation. 
All mines under the Institutional Control Program are listed on the Institutional Control Registry (the Registry). ${ }^{209}$ The Registry identifies the inspection schedule for each site to confirm that the site remains stable. Inspection reports are reviewed and approved before being entered into the Registry. Prior to being accepted into the Institutional Control Program, the operator must deposit an amount sufficient to cover the anticipated future monitoring and maintenance costs for the closed site, a fee, and an amount for unforeseen events. ${ }^{210}$ While the responsibility for monitoring and maintaining the site are transferred to the government, the majority of the costs are borne by industry.

The Saskatchewan system is based on the premise that making companies responsible for the perpetual care and maintenance of former uranium mines will be a significant barrier to investment in new developments and, further, that holding companies responsible is a suboptimal solution in any event, since we cannot expect companies to exist in perpetuity. ${ }^{211}$ In contrast, governments are institutions that operate on those time horizons, and that do have the interests of the general public in mind. The most important idea that emerges from this review is a possible system for providing for long-term monitoring managed by the state but paid for upfront by the operator (or those who contribute $\mathrm{CO}_{2}$ to the CCS project), with the state assuming responsibility once post-abandonment site stability has been demonstrated.

\section{ThE OIL SPILl Liability Regime}

There is a significant literature in international law dealing with the creation of civil liability regimes for hazardous activities. ${ }^{212}$ The best known such regime is that which exists for liabilities associated with spills from oil tankers. The regime is based on two conventions and their related protocols: the International Convention on Civil Liability for Oil Pollution Damage, 1992 and the International Convention on the Establishment of an International Fund for Compensation for Oil Pollution Damage, $1992 .{ }^{213}$

There are, of course, significant differences between the liabilities associated with oil tanker spills and the liabilities associated with CCS projects. Perhaps the key difference is that oil spill liability is associated with a particular event or accident, whereas CCS liability needs to address not only those scenarios, but also other issues such as the costs associated with re-abandonment and chronic leaks. However, the literature on the tanker regime does

209

S. 6.

Ibid., s. 5(b).

Eric Cline, "Saskatchewan's New Framework for the Long-term Management of Former Uranium Mine Sites" (2006) Nuclear Energy Review 56, online: Touch Briefings < http://www.touchbriefings.com/pdf/ 2402/cline.pdf>.

See Anne Daniel, “Civil Liability Regimes as a Complement to Multilateral Environmental Agreements: Sound International Policy or False Comfort?” (2003) 12 R.E.C.I.E.L. 225; Jutta Brunée, “Of Sense and Sensibility: Reflections on International Liability Regimes as Tools for Environmental Protection" (2004) 53 I.C.L.Q. 351; Robin R. Churchill, "Facilitating (Transnational) Civil Liability Litigation for Environmental Damage by Means of Treaties: Progress, Problems, and Prospects” (2001) 12 Y.B. Int'l Env. L. 3.

213 Both conventions [Civil Liability Convention; Fund Convention] are conveniently collected and consolidated: see International Oil Pollution Compensation Funds (IOCP Funds), Liability for Oil Pollution Damage: Texts of the 1992 Conventions and the Supplementary Fund Protocol (2005 Edition) online: IOCP Funds <http://www.iopcfund.org/npdf/ Conventions\%20English.pdf> [Liability for Oil Pollution Damage]. 
serve to draw attention to a number of key design issues, including: the form of liability, the chanelling of liability, the scope of liability, compulsory insurance, limitations on liability, and an industry levy.

It is most convenient to describe the two conventions sequentially, bearing in mind that the Fund Convention is designed to provide supplementary coverage. The basic scheme of the Civil Liability Convention is to channel liability for a spill to the ship's owner rather than to other possible parties who might be implicated, including the charterer of the vessel, the owner of the cargo, the captain and crew. ${ }^{214}$ Liability is strict, subject to conventional exceptions. ${ }^{215}$ But the Civil Liability Convention also caps liability (unless there is evidence of malice or recklessness), with the cap based on the tonnage of the vessel. In return, the ship's owner must maintain insurance to the level of the liability cap. ${ }^{216}$ The liability limits are specified in terms of special drawing rights as defined by the International Monetary Fund; currently, the maximum liability for the largest vessels is capped at approximately US\$142 million. ${ }^{217}$

The Fund Convention kicks in when the fund constituted by the tanker owner proves inadequate. Thus, the Fund Convention provides an additional tranche of liability funding based on the same strict liability principles. A key difference, however, is that the Fund under the Fund Convention is constituted by payments not from the tanker owner or another part of the tanker industry, but instead by payments made by the receivers or importers of oil. ${ }^{218}$ The Fund Convention is also subject to a cap, ${ }^{219}$ although subsequent amendments and protocols have served to raise the liability levels. ${ }^{220}$

The two most important ideas that emerge from this review are the importance of channeling liability to a designated person, such as an operator/licensee, in order to avoid a multiplicity of law suits and in order to facilitate insurance, and, second, the idea of securing liability contributions from different parts of the relevant industries.

\section{B. CCS ACCOUnTING Issues}

Unlike biological sequestration which results in the removal of $\mathrm{CO}_{2}$ from the atmosphere and therefore results in the creation of a sink that may offset emissions in the national accounts, a CCS project is designed to ensure that $\mathrm{CO}_{2}$ is never released to the atmosphere. Thus, $\mathrm{CO}_{2}$ that is captured and stored does not enter into the national accounts as an emission. However, the national accounts of a party to the Kyoto Protocol will have to deal

Civil Liability Convention, ibid., art. III(4) affords protection to these and other persons such as salvors. Ibid., art. III(2).

Ibid., art. VII.

See Secretariat of the IOPC Funds, “The International Regime for Compensation for Oil Pollution Damage,” Explanatory Note (December 2007), online: IOPC Funds <http:/www.iopcfund.org/ npdf/genE.pdf $>$ at 2 [Secretariat Note].

Fund Convention, supra note 213, art. 10.

The current liability of the Fund is capped at about US\$321 million per incident, including the sums paid by the ship owner (or insurer): Secretariat Note, supra note 217 at 3.

See in particular the Protocol of 2003 to the International Convention on the Establishment of an International Fund for Compensation for Oil Pollution Damage, 1992 in Liability for Oil Pollution Damage, supra note 213 at 53. 
with such things as the incomplete capture of $\mathrm{CO}_{2}$ either from the original waste stream or at subsequent compression facilities, as well as leakage from transportation facilities such as pipelines. It is also clear that a country will need to be able to ascertain and account for leakage from storage/disposal reservoirs. It will also be necessary to deal with the allocation of the accounting responsibility for a $\mathrm{CO}_{2}$ release in a case such as Weyburn, where the $\mathrm{CO}_{2}$ is captured in the U.S. and then transported for disposal/EOR injection in Canada.

The IPCC offered guidance on these matters for the first time in its 2006 IPCC Guidelines for National Greenhouse Gas Inventories. ${ }^{221}$ Given the inadequacy of empirical evidence allowing the estimation of emissions for accounting purposes, the IPCC has developed a recommended methodology that calls for, inter alia, both modelling to predict the fate of $\mathrm{CO}_{2}$ over centuries to millennia, and the adoption of monitoring programs including post-injection monitoring.

The IPCC also specifically addressed a series of transboundary CCS scenarios. In the first scenario (which mirrors the Weyburn project, except that Weyburn is an EOR project rather than a disposal project) $\mathrm{CO}_{2}$ is captured in country A (the U.S., in the Weyburn example) and exported for storage/disposal to country B (Canada, in the Weyburn example). The IPCC states that:

Country A should report the amount of $\mathrm{CO}_{2}$ captured, any emissions from transport and/or temporary storage that takes place in Country A, and the amount of $\mathrm{CO}_{2}$ exported to Country B. Country B should report the amount of $\mathrm{CO}_{2}$ imported, any emissions from transport and/or temporary storage (that takes place in Country B), and any emissions from injection and geological storage sites. ${ }^{222}$

Hence, in this scenario as applied to Weyburn, Canada is the location of the disposal/storage site that assumes the accounting liability for any subsequent failure in the Weyburn sequestration.

In a second scenario the $\mathrm{CO}_{2}$ is injected in country $\mathrm{A}$, but migrates from the storage/disposal site and leaks in country B. In this case:

\footnotetext{
Country A is responsible for reporting the emissions from the geological storage site. If such leakage is anticipated based on site characterization and modelling, Country A should make an arrangement with Country B to ensure that appropriate standards for long-term storage and monitoring and/or estimation of emissions are applied (relevant regulatory bodies may have existing arrangements to address cross-border issues with regard to groundwater protection and/or oil and gas recovery). ${ }^{223}$
}

A third scenario deals with a storage/disposal site in country B that is used by a number of different countries. In this scenario, as in the first, it is country B that is to report and accept responsibility for any leakage. 
In addition to the international issues, there could also be domestic statutory liability. This issue will need to be explored once federal and provincial greenhouse gas legislation develops and becomes more specific and detailed.

\section{CONCLUSIONS}

Carbon capture and storage has the potential to contribute to a suite of greenhouse gas mitigation measures. The principal obstacle to the adoption of CCS is the economics of the capture phase. However, it will also be important to resolve some outstanding legal issues associated with storage/disposal before CCS can be adopted on a broad basis in Alberta. In this article we have reviewed a set of legal issues under each of three headings: property issues, regulatory issues, and liability issues.

Under the heading of property issues, we think that the Alberta regime requires the following changes/clarifications:

- There is a need to clarify the ownership of disposal rights where there is a split mineral title. This clarification might be modeled on the current s. 57 of the MMA dealing with storage rights.

- There is a need to clarify the disposition system that the Crown adopts for disposal rights. The current scheme, based on letters of consent under s. 56, is inadequate and fails to reflect the scarcity value of the storage/disposal resource.

- There is a need to clarify the (non-) application of the Water Act to $\mathrm{CO}_{2}$ injection into a saline aquifer. This might be achieved by amending the regulations so as to provide that a $\mathrm{CO}_{2}$ disposal well is not an activity that requires approval under that Act. Such an amendment might also confirm that the statutory vesting clause includes the exclusive right to dispose of substances into Crown-owned water.

We have concluded that the surface rights regime does not require any amendment in order to accommodate CCS insofar as an operator already has a right of access to drill a $\mathrm{CO}_{2}$ disposal well under s. 13 of the SRA.

Under the heading of regulatory issues we think that the following changes are required:

- Amend the OGCA to deal explicitly with CCS schemes.

- Amend Directive 065 to create a new part to deal with CCS schemes. The new part should draw upon those existing parts of the Directive dealing with EOR, gas storage, and AGD schemes as relevant. The new provisions should pay particular attention to post-closure monitoring requirements, and should require assignment of well licences to the operator of the storage project within the project boundaries.

- Amend the Environmental Assessment (Mandatory and Exempted Activities) Regulation to list CCS (perhaps above a certain threshold) as a mandatory activity. 
Under the heading of liability issues, we propose the following:

- Development of a remedial liability regime for CCS operations. Such a scheme might be based on the Orphan Fund principles, but liability to contribute to any levy should be tailored in an appropriate way to those involved in CCS operations.

- Consideration should also be given to expanding the scope of claims that might be made against a CCS Fund so as allow claims to be made by third parties who suffer harm as a result of a CCS release event.

- The liability scheme for CCS operations should require the CCS operator to obtain the licences for all abandoned wells in the CCS approval area, and Directive 006 should be modified to allow for transfer of such wells even if they are currently restricted. 